\author{
(c) 2018. This manuscript version is made available under the CC-BY-NC-ND 4.0 license http:// \\ creativecommons.org/licenses/by-nc-nd/4.0/
}

\title{
What Drives Vertical Fiscal Interactions? Evidence from the 1980 Crude Oil Windfall Act*
}

\author{
Fidel Perez-Sebastian ${ }^{\dagger}$ \\ Ohad Raveh ${ }^{\ddagger}$ \\ U. Alicante and U. Hull \\ Hebrew University of Jerusalem
}

October 2018

Forthcoming in Regional Science and Urban Economics

\begin{abstract}
In economies with multi-level governments, why would a change in the fiscal rule of a government in one level lead to a fiscal response by a government in a different level? The literature focused primarily on the standard common-pool problem, while giving little attention to the potential role of complementarity or substitutability (CS) between the public goods supplied by the two governments. This paper fills this gap by focusing on the latter channel. First, we illustrate its potential key role in determining the sign of the vertical reaction through a generic model of vertical fiscal interactions. Second, we propose a novel strategy for identifying it, by considering an empirical design that confines the common-pool channel to specific locations. We implement this design through a quasi-natural experiment: the 1980 U.S. Crude Oil Windfall Act, which increased federal tax collections from sale of crude oil, thereby affecting the tax base of oil rich states specifically. This latter feature enables attributing the vertical fiscal reactions of the remaining states to the CS channel. Following this strategy, via a difference-in-differences approach, we decompose the sources of the vertical fiscal reactions arising from this federal tax change and find that those attributed to the CS channel: (i) account for approximately $38 \%$ of the overall vertical fiscal response; (ii) point at complementarity between state and federal public goods, most notably in transportation and welfare expenditures; (iii) are manifested primarily via changes in states' sales and income taxation.
\end{abstract}

JEL classifications: H77, H71, Q32

Keywords: Federalism, vertical fiscal reactions, common-pool problem, complementarities, natural resources

${ }^{*}$ We thank David Agrawal, Ziv Bar-Shira, Thushyanthan Baskaran, Julie Cullen, Israel Finkelshtain, Yaniv Reingewertz, Gerhard Toews, Tony Venables, and seminar participants at the Bank of Israel, Hebrew University of Jerusalem, and University of Oxford for helpful comments and suggestions. We acknowledge outstanding research assistance by Mark Rozenberg, and Maayan Segev. Raveh gratefully acknowledges financial support from the Center for Agricultural Economic Research. All errors are our own. The paper circulated previously under the title: "On the Role of State-Federal Complementarities in Vertical Tax Externalities: Evidence from the 1980 Crude Oil Windfall Act".

${ }^{\dagger}$ Fundamentos del Análisis Económico (FAE), University of Alicante; Hull University Business School; email: F.Perez-Sebastian@hull.ac.uk.

${ }^{\ddagger}$ Department of Environmental Economics and Management, Hebrew University of Jerusalem; email: ohad.raveh@mail.huji.ac.il 


\section{Introduction}

In multi-level governments such as federations, where each level acts as a separate fiscal authority, a change in the fiscal rule of a government in one level may create a fiscal response by a government in a different level, thus creating vertical fiscal interactions. This issue has taken a central role in the fiscal federalism literature, with recent studies examining the various theoretical and empirical aspects of it. One foundational question that emerges from this literature relates to the underlying sources: what drives vertical fiscal interactions? Previous seminal studies focused primarily on the standard common-pool problem: taxing a shared tax base, a change in the tax rate of one government level affects the tax base of the other, leading to a fiscal response by the latter. ${ }^{1}$ The literature, however, gave little attention to the potential role of an additional factor: state-federal complementarities or substitutabilities (henceforth, CS). ${ }^{2}$ When one government changes its fiscal policy, the other may respond due to complementarities or substitutabilities between the public goods supplied by the two governments. In this paper we fill this gap by focusing on the latter channel. Specifically, we illustrate its role in determining the sign of the vertical fiscal response, and provide empirical evidence for its sign, magnitude, and relative importance compared to the common-pool mechanism, through a specific empirical design.

The notion of state-federal complementarities in public goods dates back to the fundamental allocative principle in fiscal federalism of fiscal equivalence (e.g. Inman and Rubinfeld (1997), and Olson (1969)), motivating the coexistence of multiple levels of jurisdictions; governments provide public goods based on correspondence between the geographical boundaries of the jurisdictions and those of the benefits derived from the supplied public goods, potentially leading to complementary public good provision between the two levels of governments. ${ }^{3}$ An opposing school of thought, how-

\footnotetext{
${ }^{1}$ See Boadway and Keen (1996), Boadway, Marchand, and Vigneault (1996), Dahlby and Wilson (2003), Keen (1998), and Keen and Kotsogiannis (2002). In effect, this channel refers to the cohabitation of the tax base. While receiving various titles in the literature, we follow Dahlby (1996) and refer to it as the common-pool channel given its reminiscence to the more general common property resource problem.

${ }^{2}$ Keen (1998) discusses the option of CS-driven vertical fiscal externalities, but focuses his analysis on the commonality of tax bases. Dahlby (1996) considers the role of state-federal CS effects within the context of designing a system of intergovernmental grants, without analyzing their role in the vertical response. Hafer and Landa (2007) model the relation between federal and state public goods in a formal federalism framework; however, they do not consider vertical fiscal externalities. More generally, the related theoretical literature remains agnostic about the role of the relationship between state and federal public goods. It either employs a general utility function with no assumptions over the interaction between state and federal public goods, or uses separable demands while excluding one of the types of public goods from the set of preferences.

${ }^{3}$ Evidence on the so-called Flypaper Effect support this. Examining state-level spending responses to federal grants, various studies estimate that an inflow of federal grants can increase state spending by a factor higher than 1 (see Gramlich (1977), Hines and Thaler (1995), and Inman (2008) for surveys). This crowding-in evidence can be interpreted as indirectly pointing at potential complementarity between federal and state spending. We say indirectly because these studies focus mainly on unconditional grants, and hence primarily on the dynamics of windfall-based income effects rather than complementarities in public good provision.
} 
ever, highlights the possibility of substitutability between the different types of public goods (e.g. Knight (2002)). ${ }^{4}$ Put together, the literature suggests that while the evidence on the relationship is inconclusive, its existence is an applicable feature of the data, making it a potential driver of vertical fiscal relations.

To better illustrate the possible role of state-federal CS relationships in vertical fiscal relations, as well as their interaction with the common-pool channel, let us think of the following hypothetical motivational example: a federal government increases its tax rates over labor income to finance a new inter-state highway, leading to a negative labor supply shock. On one hand, this creates a common-pool problem as it erodes states' tax revenues from labor income. This, in turn, may lead state governments to increase their tax rates to be able to maintain the pre-shock level of public goods. ${ }^{5}$ On the other hand, however, states may also wish to invest in complementary infrastructure, such as side roads, to properly connect their residents to the newly built inter-state highway. In this case they may also raise their tax revenues via increases in tax rates, yet this time due to a complementarity effect.

Obviously, the example assumes state-federal complementarities, making the common-pool and CS channels go in the same direction. In such a case the overall vertical tax reaction is positive. However, under a different scenario where the state and federal public goods are substitutes, for instance if the federal government invests directly in states' side roads rather than in an inter-state highway, the two mechanisms would go in opposite directions. Indeed, with sufficient substitutability the overall vertical tax reaction may be negative. This highlights the potential key role that the nature of the CS relationship may take in vertical interactions.

Illustrating this analytically is our first objective. Our second objective is building an empirical design that enables identifying the CS-driven vertical fiscal reactions. Empirically disentangling states' vertical fiscal responses triggered by eroded tax bases from those occurring through the CS channel is a challenging task. To the best of our knowledge, this paper makes a first attempt to do so, through a specific design that controls the boundaries of the common-pool effect by relating it to an immobile tax base: natural resources - a potentially significant source of income with an inherent, geographically entrenched, immobility.

With these goals in mind, we construct a federalism model of vertical fiscal interactions, mo-

\footnotetext{
${ }^{4}$ More generally, the type of association observed, whether complementarity or substitutability, may depend on the type of fiscal shock, its characteristics, and the expenditure categories affected by it. For instance, some federal spending programs are dependent on state-level matching, creating complementarity by construction.

${ }^{5}$ Notably, the sign of the change depends on various factors such as, for instance, the elasticity of demand for the taxed good (Keen (1998)). We, thus, assume for the sake of the example that labor demand is relatively inelastic, and that the optimal level of public good provision did not change following the federal tax change due to, for example, a change in private consumption. Later, when studying this effect analytically, we show the latter may indeed push the outcome in the opposite direction.
} 
tivated by the frameworks of Keen (1998), Besley and Rosen (1998), and Keen and Kotsogiannis (2002). In the model, the level of government spending is chosen endogenously. To finance the budget, federal and state governments tax several shared tax bases. Unlike previous literature, the role of this cohabitation is studied in detail along with the role of the degree of complementarity (and equivalently, substitutability) between the public goods supplied by each government. This setting, which incorporates both the common-pool and CS channels into the same framework, enables studying how the two interact given a federal fiscal shock and state-heterogeneity in the tax bases. ${ }^{6}$

The analysis delivers two main predictions. First, the common-pool and CS effects can be, in general, positive or negative and push in the same or opposite directions. However, when standard functional forms are introduced in the model and specific tax cases analyzed, the common-pool and CS channels become negative and positive, respectively. As a consequence, if the complementarity between federal and state public goods is sufficiently high, states' tax rates increase with an increase in the federal tax rate. This result illustrates analytically the key role that the CS channel can take in determining the sign of the vertical tax reaction, motivating our focus on it. Second, an increase in the federal tax on a commodity that is immobile and only available in some states, like natural resources, erodes the tax base of states that own it, thus limiting the common-pool channel to these areas. Importantly, under such circumstances, fiscal reactions coming from the remaining states can be attributed to the CS channel, hence enabling its identification.

Following the latter insight, we study a quasi-natural experiment that mimics the analytical design: the 1980 U.S. Crude Oil Windfall Act (henceforth, COWA), under which excise taxes over the sale of crude oil increased based on a pre-set formula dependent on the international price of crude oil. Through this act, which was eventually repealed in 1988, the federal government collected approximately $80 \$$ billion over a period of 7 years (1980-1986) with an aim to assist low-income households, fund mass transit, and invest in the exploration of new energy sources; objectives that we show were largely met. Notably, all of the tax receipts were essentially collected from American oil producers, hence eroding the tax base of, and confining the common-pool mechanism to, oil rich states specifically. Controlling for factor reallocation, the vertical fiscal reactions of the remaining states can then be attributed, as the theory suggests, to the CS channel, thus enabling the assessment of its sign, magnitude, and relative importance.

Employing an annual-based state-level panel covering the period of 1963-2007, we examine states' heterogeneous fiscal reactions to the federal COWA tax collections, across levels of oil abun-

\footnotetext{
${ }^{6}$ We focus our discussion on top-to-bottom shocks given the nature of the quasi-natural experiment that we examine.
} 
dance. The treatment effect for this analysis is constructed in two stages. In the first stage we estimate the fitted values of state-specific regressions of the COWA tax collections on the federal expenditures in each state (net of transfers and direct payments to individuals). In the second stage we merge these fitted values together. This, in turn, yields a measure of the COWA-driven federal expenditures in each state during the treatment years (1980-1986). We then employ this measure in the analysis, via a difference-in-differences methodology. The identification strategy rests on the plausibly exogenous nature of the treatment (COWA-based) and treatment group (subset of states with geographically-based natural endowments), as well as on a likely common-trend in non-treatment years. We elaborate on these key points in the empirical part.

Following this methodology we estimate the vertical fiscal reaction of each state-group (oilrich vs. oil-poor) to the federal tax shock, and use the estimates to decompose the vertical tax responses to their two main sources: common-pool and CS. We find that the portion of the responses attributed to the CS channel: (i) account for approximately $38 \%$ of the overall vertical fiscal response; (ii) point at complementarity between state and federal public goods, most notably in transportation and welfare expenditures; (iii) are manifested primarily via changes in states' sales and income taxation. We show that the main results are robust to various controls, specifications, sample restrictions, as well as resource abundance and tax measures.

The paper relates to three strands of literature. First, the empirical literature on vertical tax externalities, including Besley and Rosen (1998), Devereux, Lockwood, and Redoano (2007), Esteller-More and Sole-Olle (2001), Fredriksson and Mamum (2008), Goodspeed (2000), Hayashi and Boadway (2001), Hoyt (2001) and Reingewertz (2018), which examine the effects of various federal tax shocks on different tax bases over multiple time periods and countries. The findings of these studies are jointly inconclusive, providing opposing evidence on the sign of the vertical tax externality. Importantly, their estimates include both the common-pool and CS components, without distinguishing between them. We contribute to this literature by illustrating the potential importance of the CS channel, showing that its sign and magnitude may determine the sign of the vertical externality. This, in turn, may reconcile their opposing findings, calling for the concurrent consideration of both mechanisms in future related empirical work. In addition, by disentangling the two channels, we provide more direct evidence on the common-pool-driven vertical fiscal externalities, finding that they are negative in our experiment.

Second, the literature on fiscal competition (see Wilson (1999), Wilson (2015), and Wilson and Wildasin (2004) for a synthesis of this vast literature). The majority of studies focus on competition in tax rates; however, competition may occur in other fiscal instruments. As noted by Wildasin (1988), when competition is not perfect this distinction may yield different outcomes, with 
potentially important implications. Our results, primarily via the notable importance of the CS channel in vertical reactions, support the view that tax rates may adjust to changes in expenditures, thus highlighting the relevance of distinguishing between these forms of fiscal competition.

Third, the literature on the optimal number of government layers. Since the seminal work of Tiebout (1956), a body of literature has emerged stressing the benefits of having overlapping governments based on efficiency grounds (Oates (1972) and Qian and Roland (1998)). Conversely, other studies critique this view, arguing that it does not account for inter-governmental strategic behaviors that may lead to inefficiencies via fiscal common-pool problems (Berry (2008), Knight (2006) and Poterba and von Hagen (1999)). We contribute to this literature by showing that even when inter-dependencies among different layers are accounted for, fiscal comovements between different layers may be efficient due to complementarities in public goods. Moreover, since these studies do not account for the CS channel, our results suggest that they may be over-estimating the said inefficiencies.

The paper is structured as follows. Section 2 presents the model. Section 3 undertakes the empirical analysis, outlining the empirical design, data, and results. Section 4 concludes.

\section{Analytical Framework}

In this section we lay out a simple analytical framework to present the role of state-federal CS relationships in vertical fiscal interactions, alongside the standard common-pool mechanism. In addition, the model illustrates the type of federal tax shock that enables identifying the CS channel and its relative importance in the vertical interactions; an important feature that will serve to motivate the design of the empirical analysis in the next section.

There could be several formalizations that deliver our main insights. We adopt the simplest one that allows studying the vertical externalities arising from the interrelated tax-setting behavior of the federal and state governments in a federation. We adopt a generic framework that follows the work of Keen (1998), and Besley and Rosen (1998). In particular, we extend Keen (1998)'s theoretical analysis to allow for multiple tax rates and study in detail the different effects that drive vertical externalities. For this, we only need to specify the consumption side of the model. More specific cases that incorporate particular functional forms and a production side of the economy, and focus on the tax rates analyzed later in the empirical section - namely, severance, income, sales, and corporate taxes - are presented in the Appendix.

Consider a nation composed of a central (federal) government, and $Z$ fiscally autonomous states, each with its own government and populated by a fixed mass of consumers of size one. ${ }^{7}$ Let us focus

\footnotetext{
${ }^{7}$ Making labor mobile should not affect our main results, provided that we are interested in disentangling the
} 
on state $s$. Governments can impose taxes on $N$ commodities and/or production inputs to finance the supply of public goods. The state operates under a balanced budget so that total revenues equal total spending, that is,

$$
t_{s}^{\prime} b_{s}=g_{s}
$$

where $t$ is the vector of tax rates $\left\{t_{1 s}, . ., t_{N s}\right\}, b$ is the vector of tax bases $\left\{b_{1 s}, . ., b_{N s}\right\}$, with $b_{j s} \geq 0$ and $t_{j s} \in[0,1)$, and ' denotes transposed.

Similarly, the federal government imposes a collection of tax rates $T$ on a vector of tax bases $B$ to finance a federal public good $G$ such that

$$
\frac{T^{\prime} B}{Z}=G
$$

Budget constraint (2) says that all states receive the same amount $G$. The model, therefore, assumes partial equalization by the federal government. ${ }^{8}$ This phenomenon stands at the heart of our main mechanism as it enables the occurrence of a fiscal asymmetry across regions. Such asymmetry is observed in the vast majority, if not all, of federations. ${ }^{9}$

Importantly, both levels of government can co-occupy or cohabit some tax bases so that $b$ is contained in $B$. Examples are the income tax base and the corporate tax base. Other taxes, on the other hand, like the ones on sales and property (for example, in the case of the U.S.), are only imposed by state governments. Nevertheless, even if there is no direct cohabitation of the same tax base, federal taxes can also affect the tax base of other types of state taxes. For example, federal severance taxes affect oil firms' profits, and therefore also state sales taxes collected from the consumption spending carried out by the oil firms' owners.

Assume that the state government is benevolent. ${ }^{10}$ We concentrate on the competitive equilibrium in which the relatively-small state $s$ internalizes the domestic determinants of the tax base, but takes the behavior of other states and the federal administration as given. ${ }^{11}$ More specifically,

sources of the vertical interactions. We discuss further implications of this assumption in the empirical part.

${ }^{8}$ In that sense, we abstract from explicitly modelling a federal transfer mechanism, which would not add further insights to the current framework.

${ }^{9}$ Previous studies documented large cross-state differences, even in those federations with large-scale equalization payment schemes. Boadway (2006) discusses the case of Canada, a federation with a major redistributive scheme. Partial equalization is as well observed in various developed and developing federations (Martinez-Vazquez and Searle (2007)) and in the OECD (Blochliger and Charbit (2008)).

${ }^{10}$ The government's objective, within a tax competition context, can be expressed in several forms. Other models consider a leviathan government (Brennan and Buchanan (1980)) or a semi self-interest one (Cai and Treisman (2005)). We comment on this issue later in the section.

${ }^{11}$ We focus on the competitive equilibrium. Notice however that the key is the assumption that states take the behavior of all other governments as given. This looks sensible to us if we think of states as small economies. Then, an alternative focus on the Nash equilibrium or considering the federal government as a Stackelberg leader should not have any significant impact on our qualitative results. 
state $s$ chooses the level of tax rates to maximize the representative-consumer's utility as follows:

$$
\max _{t_{s}}\left\{u\left(c_{s}, g_{s}, G\right)=v(c)+\Gamma\left(g_{s}, G\right)\right\}
$$

subject to equations (1), (2), and

$$
c_{s}=c\left(t_{s}^{\prime}, T^{\prime}\right)
$$

where $c_{s}$ is the aggregated value of the consumption bundle in state $s$.

The consumption function $c\left(t_{s}^{\prime}, T^{\prime}\right)$ is decreasing in each of the tax rates, in accordance with the notion that higher taxes reduce the spending capacity of households. The functions $v(\cdot)$ and $\Gamma(\cdot)$ are, in turn, increasing and strictly concave. In addition, the cross-partial derivation of $\Gamma(\cdot)$ can be larger than or equal to zero. Notice that if this cross derivative is strictly positive, the public goods $g_{s}$ and $G$ are complements. Following the initial motivational example, $g_{s}$ may complement $G$ when, for instance, the federal government builds cross-state transportation infrastructure within state $s$ for which the state government would like to connect via further local infrastructure built using its own budget. We assume for simplicity that $\Gamma(\cdot)$ is the same across states. ${ }^{12}$

The first order conditions (FOCs) for this problem provide the optimal decisions. Focusing on tax rate $t_{j s}$, the related $\mathrm{FOC}$ is

$$
\frac{\partial v\left(c_{s}\right)}{\partial t_{j s}}+\frac{\partial \Gamma\left(g_{s}, G\right)}{\partial g_{s}} \frac{\partial g_{s}}{\partial t_{j s}}=0
$$

The first term in the left hand side (LHS) gives the decline in the marginal utility of consumption motivated by an increase in tax rate $t_{j s}$. The second summand captures its marginal benefit, due to the increase in the supply of the public good $g_{s}$ permitted by a larger tax collection. At the optimum, the marginal benefit and the marginal cost must be equalized.

A main goal of our analysis is understanding how a change in a federal tax rate - say $T_{i}-$ modifies the optimal state tax rate $t_{j s}$. Applying the implicit function theorem to expression (5) obtains

$$
\frac{d t_{j s}}{d T_{i}}=\frac{\frac{\partial^{2} v\left(c_{s}\right)}{\partial t_{j s} \partial T_{i}}+\frac{\partial \Gamma\left(g_{s}, G\right)}{\partial g_{s}} \frac{\partial^{2} g_{s}}{\partial t_{j s} \partial T_{i}}+\frac{\partial^{2} \Gamma\left(g_{s}, G\right)}{\partial g_{s} \partial T_{i}} \frac{\partial g_{s}}{\partial t_{j s}}}{-\frac{\partial}{\partial t_{j s}}\left[\frac{\partial v\left(c_{s}\right)}{\partial t_{j s}}+\frac{\partial \Gamma\left(g_{s}, G\right)}{\partial g_{s}} \frac{\partial g_{s}}{\partial t_{j s}}\right]} .
$$

Note that the denominator of (6) is equal to minus the second derivative with respect to the decision variable in maximization problem (3) evaluated at the maximum, which means that the denominator is always positive.

Therefore, the change in $t_{j s}$ induced by a change in $T_{i}$ depends exclusively on the impact of

\footnotetext{
${ }^{12}$ We discuss further implications of this assumption in the empirical part. As will be evident, it does not affect the identification strategy.
} 
the federal tax on the terms that composed FOC (5). In the numerator of (6) we can identify three different effects of $T_{i}$ : (i) a marginal utility effect given by $\partial^{2} v\left(c_{s}\right) /\left(\partial t_{j s} \partial T_{i}\right)$; (ii) a marginal revenue effect captured by $\partial^{2} g_{s} /\left(\partial t_{j s} \partial T_{i}\right)$ times $\partial \Gamma\left(g_{s}, G\right) / \partial g_{s}$; and (iii) a public-good CS effect, given by $\partial g_{s} / \partial t_{j s}$ multiplied by the impact of the variation of $T_{i}$ on the weight $\partial \Gamma\left(g_{s}, G\right) / \partial g_{s}{ }^{13}$

The marginal utility and marginal revenue effects are closely interrelated, because most taxes have a direct impact on both government revenues and households' spending capacity. More specifically, when a federal tax rate rises, it reduces the state tax base because of cohabitation. The decline in the tax base further reduces both the state government revenue and the consumer's income. Given this, we refer to the join marginal-utility/marginal-revenue effect as the common-pool mechanism. ${ }^{14}$

The above definition of the public-good CS effect implies that if the state behaved, instead, as a leviathan that simply maximizes revenue, the CS effect would not play any role. Notice that maximizing revenues only requires the equalization of the marginal revenue to zero. Therefore, evidence in favor of a role of the CS effect can be also interpreted as evidence against a pure leviathan behavior.

Equation (6) has no clear sign because the three summands in its numerator can be positive or negative. Starting with the first one, we can decompose the marginal utility as $\partial v\left(c_{s}\right) / \partial c_{s}$ times $\partial c_{s} / \partial t_{j s}$. The decline in consumption induced by a higher federal tax rate tends to decrease $\partial c_{s} / \partial t_{j s}$ but increases the marginal utility because $\partial v\left(c_{s}\right) / \partial c_{s}<0$. Thus the overall change in $\partial v\left(c_{s}\right) / \partial t_{j s}$ is ambiguous.

Moving to the marginal revenue, the term $\partial \Gamma\left(g_{s}, G\right) / \partial g_{s}$ is strictly positive. This implies that the sign of the second summand in the numerator of equation (6) is exclusively given by $\partial^{2} g_{s} / \partial t_{j s} \partial T_{i}$. Employing the state government budget constraint, expression (1), and taking into

\footnotetext{
${ }^{13}$ Let us compare these effects with the ones analyzed by Besley and Rosen (1998) and Keen (1998). Like us, Besley and Rosen (1998) consider an array of state and federal taxes. However, they mainly look at the state response to a federal tax change when the goal is to raise a fixed amount of revenue. From their setup, Besley and Rosen (1998) describe a deadweight loss effect similar to (i), and a revenue effect and a tax-related CS effect that jointly can resemble (ii). The model presented by Keen (1998) is, on the other hand, closer to ours. Specifically, in this model federal tax rates may affect the chosen level of $g_{s}$. Nonetheless, unlike us, he focuses on a single instrument to raise revenue and on the effects related to the co-occupation of the tax base (common-pool). Therefore, neither of these two papers disentangles the public-spending CS effect from the common-pool one.

${ }^{14} \mathrm{~A}$ clearer way to show that the effect that works through the marginal utility can also be considered to be part of the common-pool channel is, for example, by looking at the state sales (or consumption) tax. In this scenario, an increase in the federal rate could reduce consumption expenditure, and therefore state tax revenues. This case is analyzed in the Appendix. Importantly, it leads to the same main insights.
} 
account that a change in the state tax rate $t_{j s}$ can modify several tax bases, we can write:

$$
\frac{\partial^{2} g_{s}}{\partial t_{j s} \partial T_{i}}=\frac{\partial}{\partial T_{i}}\left\{b_{j s}\left[1-e_{b_{j s}}\left(t_{j s}\right)\right]+\sum_{\substack{v=1 \\ v \neq j}}^{N} b_{v s} \frac{t_{v s}}{t_{j s}} e_{b_{v s}}\left(t_{j s}\right)\right\} ;
$$

where $e_{b_{j s}}\left(t_{j s}\right)$ denotes the elasticity of the tax base $b_{j s}$ to its own tax rate $t_{j s}$, and $e_{b_{v s}}\left(t_{j s}\right)$ represents the cross elasticity of the tax base $b_{v s}$ to the tax rate $t_{j s}$.

Hence, the sign of the marginal revenue effect depends on how the federal tax rate affects the elasticities. This is the same insight as the one offered by Keen (1998) but extended to multiple possibly interrelated taxes. As a corollary, because both the marginal utility and the marginal revenue can increase or decrease when there is a federal tax-rate shock, the common-pool effect can be positive or negative.

Finally, we look at the CS channel. The sign of the term $\partial^{2} \Gamma\left(g_{s}, G\right) /\left(\partial g_{s} \partial T_{i}\right)$ will be positive when the two public goods are complements - i.e., if $\partial^{2} \Gamma\left(g_{s}, G\right) /\left(\partial g_{s} \partial G\right)>0$ - because $\partial g_{s} / \partial T_{i} \leq 0$ and $\partial G / \partial T_{i}>0$ always. ${ }^{15}$ On the other hand, the sign of $\partial^{2} \Gamma\left(g_{s}, G\right) /\left(\partial g_{s} \partial T_{i}\right)$ can be positive or negative if $g_{s}$ and $G$ are substitutes. The direction of the CS mechanism also depends on the sign of $\partial g_{s} / \partial t_{j s}$. We know that this derivative is given by the terms within the curly brackets in expression (7). Hence, the sign of the CS effect depends on the elasticity of substitution between $g_{s}$ and $G$, as well as on the tax-rate elasticities of the tax bases. If, for example, the public goods are complements and $g_{s}$ rises with $t_{j s}$ then the CS effect is positive.

The common-pool and $g$ - $G$ CS effects are, therefore, both at work and can be positive or negative. This highlights a key point of the analysis: the CS channel may play an important role in understanding the sign and magnitude of the vertical tax reaction, shedding light on a point of disagreement in the literature. However, given that we can not pin down the sign with certainty, the magnitude and direction of each of these two forces become an empirical issue. Next, we obtain results that allow offering theoretical foundations to disentangle the two mechanisms.

Suppose that the federal tax rate $T_{i}$ is imposed on a commodity available only in some states but not in others. In the empirical analysis, this commodity is (immobile) oil reserves. This implies that, only if state $s$ owns the commodity, the variation in the state tax rate $t_{j s}$ will be driven by the three effects defined above. However, if this is not the case, a change in $T_{i}$ will produce zero variation in the marginal utility, marginal revenue, and state revenues - that is, $\partial^{2} v\left(c_{s}\right) /\left(\partial t_{j s} \partial T_{i}\right)$,

\footnotetext{
${ }^{15}$ In principle, the sign of $\partial G / \partial T_{i}$ could be positive or negative because of the impact of $T_{i}$ on the tax bases. However, in terms of our model, more $G$ is always good, and therefore, a benevolent federal government will raise $T_{i}$ only if it increases revenues and the supply of $G$.
} 
$\partial^{2} g_{s} /\left(\partial t_{j s} \partial T_{i}\right)$, and $\partial g_{s} / \partial T_{i}$ will be equal to zero. Consequently, expression (6) will become

$$
\frac{d t_{j s}}{d T_{i}}=\frac{\left(\frac{\partial^{2} \Gamma\left(g_{s}, G\right)}{\partial g_{s} \partial G} \frac{\partial G}{\partial T_{i}}\right) \frac{\partial g_{s}}{\partial t_{j s}}}{-\frac{\partial}{\partial t_{j s}}\left[\frac{\partial v\left(c_{s}\right)}{\partial t_{j s}}+\frac{\partial \Gamma\left(g_{s}, G\right)}{\partial g_{s}} \frac{\partial g_{s}}{\partial t_{j s}}\right]} .
$$

Only revenues obtained by the federal government and the public good that it supplies will increase.

Importantly, expressions (6) and (8) suggests that it is possible to separate the CS from the other effects when there is state-heterogeneity in taxed commodities. In particular, expression (8) implies that if state $s$ does not own commodity $i$, a change in the federal tax rate $T_{i}$ affects $t_{j s}$ solely through the CS channel. Put differently, when $b_{i s}=0$ the common-pool mechanism is eliminated. Conversely, if $b_{i s}>0$, changes in $t_{j s}$ occur through all channels.

In the Appendix, we provide three specific examples that study the impact of the federal severance tax rate on capital-income, corporate, and sales state taxes. ${ }^{16}$ They show that in all cases the common-pool mechanism is negative. The ambiguity of its sign vanishes because part of the variation in the marginal revenue is neutralized by the change in the level of consumption, thus suggesting that the common-pool channel is mainly driven by the change in the marginal utility of private-good consumption. Since this marginal utility increases with $T_{i}$, the marginal utility derived from the services provided by the state public good needs to increase as well; this, in turn, causes the supply of the state public good and the state tax rate to decrease.

The CS channel is, on the other hand, always positive. This occurs because in these more specific cases the fall in the tax base of the capital-income, corporate and sales state taxes brought about by the increase in the federal tax rate is relatively small. As a consequence of these opposing forces, all else equal, weaker complementarity between $g$ and $G$ may lead state governments to react in an opposite manner to federal tax shocks due to the common pool mechanism. Conversely, sufficiently high complementarity may lead to a positive comovement in the two-level tax rates.

The most important takeaway message from our generic model and the more specific tax cases presented in the Appendix is that having a design where the federal tax shock is on an immobile tax base, and some states are sufficiently rich in it, then the sign, magnitude, and relative importance of the CS channel can be identified by observing changes in $t_{i}$ in states that do not own that type of tax base. We exploit these features in the empirical part.

In particular, in the empirical part we focus on a federal tax on extractive industries because they employ natural resources, which possess an immobile nature and are only present in some

\footnotetext{
${ }^{16}$ Results with a labor-income tax would be qualitatively the same to the ones that we obtain with corporate taxes. This is because in the model presented in the Appendix each firm is owned by an entrepreneur so that profits work like the return to labor.
} 
locations due to their inherent geographic characteristics. Then, state differences in the size of the non-mobile tax base will enable to maintain the common-pool effect within specific states. in addition, natural resources offer significant rents. As we show later when investigating U.S. states, in some cases (e.g. Alaska, Wyoming) their income can add up to more than $40 \%$ out of all income sources of the state. This, in turn, implies that tax shocks related to them may be meaningfully impactful for both the state and federal governments.

Another lesson that we extract from the theoretical analysis is that taxes are not the only force that can change tax-base levels. There exists the possibility that input movements, like capital flows, triggered by changes in states' tax rates can affect the final outcome in all states to some extent, as illustrated in more detail in the cases presented in the Appendix. This has various empirical implications which we will consider; for instance, the need to control for inter-state factor movements.

\section{$3 \quad$ Empirical Evidence}

The analytical framework illustrated the potential key role of the CS mechanism within the larger vertical fiscal dynamics. In this section we seek to provide empirical evidence for the $g-G$ CS channel, including its magnitude, sources, and relative importance compared to the common-pool channel. We do so by taking the U.S. as a case study, and exploiting a quasi-natural experiment -the 1980 Crude Oil Windfall Act- which follows the case of a change in $T_{i}$ where $b_{i s}=0$ for some of the states, thus providing a design under which the $g-G$ CS effect is potentially identifiable. Next, we discuss the details of this act, and its applicability to our case.

\subsection{The 1980 Crude Oil Windfall Act}

Throughout the 1970s the price of domestic oil was controlled by the U.S. federal government, which started decontrolling it in 1979, completing the process in 1981. Concurrently, the price of oil surged, peaking in the early 1980s, as illustrated in Figure 1. Realizing this would provide significant profits to American oil producers, the Carter Administration enacted the Crude Oil Windfall Act in 1980, which was an excise tax on domestic crude oil imposed at the wellhead. The tax was paid on the difference between the market price of oil and a base price which was set as the May 1979 oil price adjusted for inflation. The aim of the Carter Administration was, on the one hand, to prevent oil producers from reaping excessive profits and, on the other, to use the raised revenues to assist low-income households, fund mass transit, and explore new energy sources. As a commitment device, the administration proposed to put the revenues in a trust fund to ensure that they are used for these purposes. 
Given the decrease in the oil price during the 1980s, the consequent decline in revenues from the said tax (decreasing to virtually none in 1987), and various political pressures that accompanied this decline, the bill was eventually repealed in 1988. ${ }^{17}$ Therefore, revenues were collected for 7 fiscal years, during 1980-1986. Figure 2 presents the annual collections, which sum up to approximately $80 \$$ billion. This represents a relatively large magnitude compared to those produced by other federal tax changes during the 1980s. ${ }^{18}$ Nonetheless, this yields a relatively small change in the total federal revenues. Notably, previous empirical studies on vertical tax externalities in the U.S. suggest that changes of this magnitude produce noticeable fiscal reactions by state governments. ${ }^{19}$ The analysis to follow indicates that this is also the case when focusing more specifically on the CS effect.

Importantly, the federal tax is specifically on a non-mobile factor (oil sector); it hence follows the case of a change in $T_{i}$ where $b_{i s}=0$ for some of the states, presented in Section 2, creating a common-pool problem solely in the oil rich states. More specifically, the latter occurs because the tax is imposed directly on the oil producers, who in turn cannot forward it to the selling price given that it has been deregulated in the U.S. by that point and is therefore determined by global demand. The result is a decrease in domestic oil production, and hence an erosion of the tax base of oil endowed states specifically. The magnitude is non-trivial. In a report prepared by the U.S. Congressional Research Service, Lazzari (2006) estimates the COWA-driven reduction in domestic oil production during the period of 1980-1986. Appendix Table A1 outlines the annual estimated magnitudes. In 1981, for instance, COWA decreased oil production by approximately 310 million barrels, or about $8.3 \%$ of total oil output. The estimated reduction over 1980-1986 is around $4.8 \%$ of total oil output (approximately 1268 million barrels).

Additional features make this federal tax policy appealing for our purposes. First, using narrative sources Romer and Romer (2010) classified the COWA tax change as exogenous given it was motivated by long-run concerns. While their rational relates primarily to GDP, it is also applicable to state tax rates; having a long-term perspective suggests that the enactment of this act was not driven by short-term changes in state tax rates. This, in turn, contributes to considering the tax

\footnotetext{
${ }^{17}$ During this time there were several amendments made to it. Some were minor and technical, and others more substantial (under the Economic Recovery Tax Act of 1981, for instance), decreasing tax rates on newly discovered oil, and introducing a tax credit for royalty owners, among others. Nonetheless, the tax remained effective, and revenues were collected until it was repealed.

${ }^{18}$ Computing the present value of the change in federal revenues induced by major federal tax acts (reporting it at the year the acts were enacted), Romer and Romer (2010) report that COWA's expected effect on federal revenues is larger (in absolute value) than that of other major federal tax changes enacted in the 1980s, such as the Deficit Reduction Act of 1984, the Tax Reform Act of 1986, and the Budget Reconciliation Act of 1987.

${ }^{19}$ For instance, Reingewertz (2018) identifies vertical fiscal externalities using Romer and Romer's (2010) sample of federal tax changes, which includes COWA as well as other federal tax shocks of smaller magnitude.
} 
policy change itself as being plausibly exogenous. Second, as outlined above the tax collections, as well as the decision to eventually repeal the act, were primarily based on variations in the international price of crude oil. Assuming the latter is an exogenous variable determined in the global market, the annual COWA shocks we examine are plausibly exogenous as well. These features take a central role in the empirical analysis. Last, the tax change takes place in the U.S., an economy that follows the analytical framework closely in terms of presenting a federal environment with ample cross-state variation in resource abundance and non-redistributed resource income, as Figure 3 illustrates. $^{20}$

\subsection{Data and methodology}

Our objective is to decompose the states' vertical tax reactions to the federal COWA tax shocks to their CS and common-pool components, with an emphasis on identifying the former. To do so we examine the heterogeneous fiscal reactions across states' level of resource richness, via a differencein-differences approach. Next, we describe the treatment effect, treated group, methodology, and identification strategy. Starting with the treatment effect. While the experiment we examine (COWA) represents a change in federal tax policies, the vertical tax reactions of state governments are rather tied to changes in federal expenditures by state. Hence, as a first step we test whether tax receipts from COWA were translated, to some extent, to spending at the federal level in general. The analysis and results are relegated to the Appendix. ${ }^{21}$ We find that COWA revenues were indeed associated with increased public expenditure at the federal level, following the program's initial official objectives on revenue usage.

Motivated by these initial observations we construct the treatment effect. As noted, the focus is on COWA tax collections yet the vertical reactions are made, ultimately, to changes in federal expenditures. This point is central to our analysis because complementarities or substitutabilities are essentially a product of the relations of state and federal expenditures. Hence, ideally our treatment needs to capture the changes in the state-specific federal expenditures that were driven by COWA, during the treatment period. These data are not observed directly. Instead, we construct a proxy that implicitly assumes that the national COWA tax collections were allocated across states based on the relative allocations of all other federal expenditures, captured via the observed statespecific federal expenditures per capita in each state. ${ }^{22}$ We construct this proxy (treatment) in two

\footnotetext{
${ }^{20}$ We measure resource abundance by state income from severance taxes. While these taxes pertain to the production of fossil fuels in general, oil takes a central role in its composition.

${ }^{21}$ Specifically, it is discussed in Appendix C, with the results presented in Table A2, and descriptive statistics provided in Table A3.

${ }^{22}$ Later we also show for robustness that similar results are produced in case we assume that the COWA tax collections were allocated equally across the nation based on the distribution of population.
} 
stages. In the first stage we take the fitted values of the following state-specific regression, for each state $i$ separately, at year $t$, estimated over our treatment years (1980-1986):

$$
F_{t}^{i}=\alpha+\beta(C O W A)_{t}+\epsilon_{i, t}
$$

where $F^{i}$ denotes the real per capita federal expenditures in state $i$, and $C O W A$ denotes the annual tax collections from COWA. More specifically, $F^{i}$ represents the state-specific per capita federal expenditures, net of federal transfers and direct payments to individuals. This subtraction enables focusing the analysis on the portion of federal expenditures that may relate to complementarities or substitutabilities. Equivalently, it ensures that our estimates do not capture mechanic complementarities related to matching grants, or federal redistribution. Notice that a higher $F^{i}$ yields a higher $F_{F V}^{i}$ (fitted values), consistent with the allocation assumption; i.e. states in which federal expenditures are relatively higher are assumed to be equivalently allocated proportionally higher COWA-sourced federal expenditures.

A key feature of the state-specific federal expenditure data is that it is available from 1981, unlike our treatment that begins in 1980. To maximize the constructed treatment effect, we expand $F^{i}$ to 1980 based on the assumption that it is distributed equally across the nation. Under this assumption, the $F^{i}$ for 1980 is the national federal expenditures (net of transfers and payments to individuals) divided by the national population, for all $i$. This assumption is strong if the comparison is indeed across states. This is illustrated in Figure 4, which shows that $F^{i}$ (19811986) has much variation across states. However, in our difference-in-differences framework, the key comparison is between the treated and control groups (described below). Figure 5 shows that $F^{i}$ (1981-1986) exhibits little difference between the two state-groups, motivating the expansion we take for 1980. Nonetheless, later in the analysis we show that the main results hold when 1980 is excluded from the sample.

An additional key point relates to $C O W A$. While $F^{i}$ is at the state level, $C O W A$ remains to be at the national level, representing the overall annual tax collections from COWA, across all states. Maintaining the national perspective with $C O W A$ is an important feature of the empirical analysis because it follows the design of the analytical framework in which tax collections from resource rich states are translated to federal expenditures in states that are not endowed with this tax base. Translating $C O W A$ to the state level does not capture this feature because no collections were made from the resource poor states.

Moving to the second stage of the treatment construction, we take the $F_{F V}$ (fitted values) of each state, and merge them into a single treatment effect, which we denote by $C A$ (representing 
an abbreviation of COWA). ${ }^{23}$ This measure, hence, gives the COWA-driven real per capita federal expenditures in each state (net of transfers and payments to individuals), representing the treatment examined in the analysis. Importantly, it has both cross-sectional and time variation. Its basic descriptive statistics are outlined in Table 1. Notably, the mean $C A$ is around $40 \$$ (with a standard deviation of approximately 28\$). This, in turn, suggests that while the scope of COWA may be relatively small compared to the general federal revenues, the extent to which it impacts statespecific federal expenditures may nevertheless induce an observable CS effect, ${ }^{24}$ and hence enable the identification of its sign and other relevant characteristics.

Thus, the treatment we examine is $C A$, during the period of 1980-1986. The treated group ( $R R$, denoting resource rich), under the benchmark analysis, includes the states that had at least some positive income from natural resources during the treatment years; this definition applies to 32 states. The control group ( NRR, denoting non resource rich) includes the remaining 18 states. The list of states included in each group is provided in the data Appendix. Despite its inclusion of relatively resource poor states in the treated group, we adopt this division for the baseline estimation as it ensures that the tax bases of the economies in the control group are not affected by the tax policy examined.

To that end, we employ an annual-based panel of the 50 U.S. states that covers the period of 1963-2007, with which we estimate variations of the following model, for state $i$ at time $t$ :

$$
\text { taxrates }_{i, t}=\alpha+\beta(C A * R R)_{i, t-1}+\gamma(C A * N R R)_{i, t-1}+\boldsymbol{\delta}(\mathbf{X})_{i, t-1}+v_{t}+\eta_{i}+\epsilon_{i, t} .
$$

In terms of notation, taxrates represents either statutory or average tax rates. Our primary focus, however, is on the former because it is independent of the tax base. In each case, we examine the three main types of state tax rates, namely income, corporate, and sales tax rates. The statutory versions are the top income and corporate tax rates and the given sales tax rates. The average versions are measured as the GSP share of the tax revenues levied from each tax type (income, corporate, or sales). For each case (statutory or average) we construct a baseline tax rate that incorporates the three separate tax rates. In effect, this baseline version is a weighted average of the three, with the weights being the share of the tax revenues of each in their sum, in the initial year (1963). ${ }^{25}$ These weights represent the relative size of each tax base in each state. Constructing

\footnotetext{
${ }^{23}$ This method is inspired by the methodology of Frankel and Romer (1999) and Raveh and Reshef (2016). More formally, $C A_{t}^{i}=F_{F V, t}^{i}$; however, since $F V_{F V, t}$ is estimated for each $i$ separately, $C A$ represents their aggregate, across all $i$. As an example, in the first stage $F V_{F V, t}$ is estimated separately for, e.g., Alabama (AL) and California (CA); thereafter, in the second stage $F V_{F V, t}^{A L}$ and $F V_{F V, t}^{C A}$ are aggregated into $C A_{t}^{i}$, which similarly includes $F V_{F V, t}$ for all $i$.

${ }^{24}$ As the earlier discussion suggests, states do not observe the revenue source of the federal expenditures. In effect, states' reaction is to the federal expenditures, which they do observe and which are COWA-driven in the case of $C A$.

${ }^{25}$ More formally, for each state we define $s u m=i n c_{63}+\operatorname{corp}_{63}+$ sales $_{63}$, where inc $_{63} /$ corp $_{63} /$ sales $_{63}$ are
} 
them based on data in the initial year of the sample enables highlighting the general cross-state differences while mitigating endogeneity related concerns. In addition, using the same weights in both the statutory and average cases ensures that both tax rates pertain to the same underlying tax base.

The variable $C A$ denotes the treatment constructed previously. The measures $R R$ and $N R R$ are binary variables that capture the states included in each of these groups as described above. Their interaction is examined at $t-1$ because COWA collections are undertaken throughout the year and the vertical reactions, via taxrates, are expected to occur thereafter. Last, $v_{t}$ and $\eta_{i}$ are state and year fixed effects that control for unobserved time-invariant state heterogeneity, and state-invariant within-year shocks. Importantly, the latter control for changes in the oil price, which as noted are tied to the COWA revenues yet may affect local income more broadly (as indicated, for instance, by Acemoglu, Finkelstein, and Notowidigdo (2013)).

$\mathbf{X}$ is a vector that includes various relevant measures that are suggested by the model and previous research; these enter the model in $t-1$ to capture benchmark levels at the time the shock occurs. ${ }^{26}$ First, real GSP per capita, which controls for income differences; importantly, this also captures income effects manifested via changes in the oil price. Second, real per capita state expenditures, which controls for the demand for public goods. Third, real per capita intergovernmental transfers from the federal government to the states, which controls for transfer-driven state fiscal behavior (Smart (1998)). Last, annual changes in states' real per capita capital stock (derived from Garofalo and Yamarik (2002) and its extension), ${ }^{27}$ and population to control for potential factor movements that may occur due to both COWA-driven and resource-driven changes in state tax rates. ${ }^{28}$

Some further points regarding the empirical model. Its form is motivated by condition (8), and the difference-in-differences approach. ${ }^{29}$ Note that the separate components of the interaction

state tax revenues from income/corporate/sales tax in 1963, respectively. Then, weight_x $=x /$ sum, where $x \in\left(\right.$ inc $_{63}, \operatorname{corp}_{63}$, sales $\left._{63}\right)$, represent the weights for each tax type, for 1963 . Finally, the baseline tax rate at year $t$ is defined as: Baseline_tax $x_{t}=\left(i n c_{t} *\right.$ weight_inc $\left.c_{63}\right)+\left(\right.$ corp $_{t} *$ weight_corp 63$\left.)+\left(\text { sales }_{t} * w_{\text {eight_sales }}\right)_{63}\right)$. Computing Baseline_tax 1980 for the case of New York as an example, in 1963 the shares of income/corporate/sales tax revenues in their sum were $0.48,0.19$, and 0.33 , respectively. The statutory income/corporate/sales tax rates were $0.14,0.1$, and 0.04, respectively. Therefore, Baseline_tax $1980=0.14 * 0.48+0.19 * 0.1+0.33 * 0.04=0.0994$.

${ }^{26}$ Nonetheless, results remain qualitatively and quantitatively similar if these measures are considered in their contemporaneous form.

${ }^{27}$ Specifically, Garofalo and Yamarik (2002) provide these data for the pre-1997 years. Post-1996 figures are based on their extension of their original data, available on the second author's homepage.

${ }^{28}$ The model suggests, via its additional analysis in the Appendix, that changes in resource income may affect $t_{i}$. This result was discussed in previous studies that examined tax competition settings with state-heterogeneity in non-mobile endowments (Cai and Treisman (2005), Perez-Sebastian and Raveh (2016), Perez-Sebastian, Raveh, and Reingewertz (2016), and Raveh (2013)), and substantiated empirically by James (2014).

${ }^{29}$ Condition (8) suggests examining the difference in federal tax rate on the difference in the state tax rate. The variable $C A$ mimics the former, as it captures the federal expenditures triggered by the additional federal tax revenues 
terms are excluded; this is because the average $C A$ effect is absorbed by the inclusion of both interactions, and the state-division variables $(R R$ and $N R R)$ are absorbed by the state fixed effects. The inclusion of both interactions, in lieu of the average effect, stands at the center of the decomposition analysis, as we further explain below. Nonetheless, as an initial analysis, we also examine a specification in which the average effect is included in lieu of the $N R R$ interaction term. Wherever possible, explanatory variables enter the analyses in their natural logarithm form to better account for potential outliers. ${ }^{30}$ Examining the effects of a federal, common shock, we follow a relatively conservative two-way clustering approach and cluster the standard errors by state and year. Unless specified otherwise, variables are derived from the U.S. Bureau of Economic Analysis and the U.S. Census Bureau. Further sources and descriptions of all variables are outlined in the data Appendix. Table 1 provides descriptive statistics for the general sample; Appendix Table A4 provides the same, for the $R R$ and $N R R$ groups separately.

Our main focus is on the coefficients $\beta$ and $\gamma$, with a particular emphasis on the latter. Together they give the total difference in differences in the vertical tax reactions to $C A$. The total vertical response, which we seek to decompose, is the sum of common-pool and CS effects. The basic insight employed is that the fiscal reaction coming from $N R R(\gamma)$ is driven by $g-G$ complementarities or substitutabilities, once factor movements are controlled for. Hence, $\gamma$ is indicative of the CS channel. Importantly, its interpretation does not rely on additional assumptions, such as imposing equal complementarity patterns across the nation.

In turn, the fiscal reaction coming from $R R(\beta)$ is driven by both $g-G$ complementarities or substitutabilities, and common-pool effects. To be able to interpret $\beta$ as indicative of the commonpool effect we require that the degrees of the $g-G$ CS effect be similar across the $R R$ and $N R R$ groups. In such a case the common-pool-driven component can be isolated from $\beta$ by subtracting $\gamma$ from it. Nonetheless, given this additional assumption we interpret the estimates of $\beta$ with more caution, and maintain a primary focus on $\gamma$.

The identification strategy is based on various points. First, on the plausibly exogenous characteristics of COWA as described earlier, including its enactment, annual shocks, and repeal. Second, on the geographically-based nature of the state-division. Examining the list of $N R R$ states and comparing it to the long averages of resource income that appear in Figure 3 we see that these states had almost no income from resources during all sample years. Based on this observation

collected each year, due to the change in the tax rate. The latter is applicable via the difference-in-differences approach. Hence, the baseline specification examines the dependent variable in levels. Nonetheless, we show in a later sub-section that the main results are robust to the inclusion of a lagged dependent variable. In addition, as will be evident, in cases where each group is examined separately we control for a lagged dependent variable, to examine changes directly.

${ }^{30}$ This transformation does not affect the results. 
we assume that this resource scarcity is geographically entrenched, and hence plausibly exogenous. Last, on an identifying variation that relies on a common-trend between the treatment and control groups in non-treatment years, which we discuss next.

\subsection{Initial analysis}

The main specification, namely equation (10), enables observing the reactions of $R R$ and $N R R$. To motivate this form, within a difference-in-differences framework, and present a formal test of common trends in non-treatment years, we start with estimating the following, standard differencein-differences specification:

$$
\text { taxrates }_{i, t}=\alpha+\gamma(C A)_{i, t-1}+\mu(C A * R R)_{i, t-1}+\boldsymbol{\delta}(\mathbf{X})_{i, t-1}+v_{t}+\eta_{i}+\epsilon_{i, t} .
$$

The key difference from the baseline specification is the inclusion of $C A$ in lieu of $N R R *$ $C A$. In this case, therefore, $\mu$ gives the total difference in differences (equivalent to $\beta-\gamma$ in the baseline model). Results appear in Table 2. Column 1 (2) represents the case in which taxrates is the baseline statutory (average) tax rate. The precisely estimated negative $\mu$ s indicate that the treatment yields a difference in the differences, in the expected direction. This result, in turn, motivates the decomposition of this observed difference in the differences in the following (main) analysis.

Within this initial specification we can also test for common trends in non-treatment years. To do so, we consider the following model:

$$
\text { taxrates }_{i, t}=\alpha+\gamma(C A)_{i, t-1}+\mu_{z}\left[(C A * R R)_{i, t-1} * Y e a r_{z}\right]+\boldsymbol{\delta}(\mathbf{X})_{i, t-1}+\eta_{i}+\epsilon_{i, t},
$$

where $z \in(1963,2007)$, and Year $_{z}$ is a dummy for year $z$. In effect, this specification undertakes a generalized difference-in-differences estimation of equation (11), in which the total difference $(C A * R R)$ in interacted with the sample years (1963-2007), $v_{t}$ is excluded, and taxrates is the baseline statuary tax rate. ${ }^{31}$ The reference year is 1963 . The results $\left(\mu_{z} \mathrm{~s}\right.$ and their $95 \%$ confidence interval bands) are plotted in Figure 6 . As observed, $\mu_{z}$ is negative and precisely estimated only in COWA years. Conversely, in pre-1980 and post-1986 years (i.e. non-COWA periods) its magnitude (in absolute value) and statistical preciseness significantly drop. ${ }^{32}$ These patterns illustrate the common-trend in non-COWA years.

The latter point deserves further comment. A key factor in our identification strategy is the

\footnotetext{
${ }^{31}$ The variable $C A$ in this case is assigned a value of 1 in non-treatment years to identify the separate year effects.

${ }^{32}$ Notably, a plot of a generalized difference-in-differences version of the main specification, presented in the following sub-section, points at a similar observation.
} 
oil price. On one hand, it provides plausibly exogenous variation for the treatment. On the other, however, it may be argued that it contributes to the differential effect observed in treatment years. Figures 1 and 6 deliver a central observation that addresses this issue. We see in Figure 1 that the oil price changes continuously throughout our sample period; nevertheless, it does not yield an observable difference in the differences during non-treatment years in Figure 6, even in periods of extreme changes such as during the 1970s. This, in turn, suggests that the magnitude of its different effect on the $R R$ and $N R R$ groups is common throughout the sample. Hence, we can assume that it remains similar as well during treatment years. We consider further aspects of this issue in the empirical analysis, including controlling for time fixed effects and undertaking placebo tests that examine pre-COWA years.

\subsection{Benchmark results}

Next, we present the results of the main analysis, which are outlined in Table 3. Column 1 estimates equation (10), in which taxrates is the baseline statutory tax rate. This represents our benchmark specification. The estimated $\gamma$ and $\beta$ provide the key empirical insights. Starting with the former, the precisely estimated positive $\gamma$, representing the portion of the response coming from $N R R$, points at a positive CS effect. The positive sign suggests that $g$ and $G$ are on average complements; an increase in federal expenditures, via the additional COWA federal tax collections, increases the tax rates in $N R R$ states. Recall that this represents a net effect, under a sub-sample of federal expenditures. ${ }^{33}$ Nonetheless, to interpret the magnitude, a one standard deviation increase in $C A$ $(28 \$)$ increases the baseline statutory tax rate by about 0.19 percentage points, or approximately one tenth of its standard deviation. ${ }^{34}$

Moving to the latter, under the additional assumption that the degree of complementarity is similar across state-groups, the significant negative $\beta$ suggests that the common-pool effect is negative. An increase in the COWA-driven federal expenditures decreases the baseline statutory tax rates in $R R$ states due to a contraction in the oil-related tax base. By comparing $\beta$ to $\gamma$ it can be deduced that the CS-driven vertical reaction comprises approximately $38 \%$ of the total reaction ${ }^{35}$ the common-pool-driven portion accounts for the balance. To observe these patterns

\footnotetext{
${ }^{33}$ Some federal expenditures items substitute state-level ones, while others complement it. We observe the aggregate, net effect. In addition, as noted expenditure items that induce mechanic complementarity (i.e. matching grants) are excluded.

${ }^{34} \mathrm{~A}$ one standard deviation in $C A, 0.028$ (thousand $\$$ ), multiplied by the estimate on $\gamma(0.067)$ is 0.0019 , which is 0.19 percentage points, or about one tenth of the standard deviation of the baseline statutory tax rate, namely 0.02 .

${ }^{35}$ This is calculated in three steps. First, we subtract $\gamma$ from $\beta$; this yields the magnitude of the common-pool effect $(-0.041-0.067)$. Second, we take the common-pool measure in absolute value, and add $\gamma$ to it $(0.108+0.067)$; this gives the magnitude of the total vertical response. Last, we a divide $\gamma$ by the latter $(0.067 / 0.175)$; this provides the portion of the CS channel in the overall vertical fiscal reaction.
} 
graphically, Figure 7 plots the estimates obtained from estimating a version of equation (10), in which the treatment $(C A)$ is interacted with the sample years (1963-2007), for $R R$ and $N R R$, and the year fixed effects are excluded. The negative (positive) impact in $R R(N R R)$ during treatment years is clearly observed. ${ }^{36}$

In the next two columns we examine the two groups, $R R$ and $N R R$, separately to observe the distinct effects more directly, outside the scope of the difference. Column 2 examines the restricted sample of the $N R R$ states; Column 3 focuses on the remaining, $R R$ states. Because this division does not focus on the difference in differences it yields a level regression that is inconsistent with condition (8). To correct for that we estimate a dynamic version of equation (10), by adding a lagged dependent variable. In addition, the interaction terms are excluded $(C A * R R$ and $C A * N R R)$ in lieu of the average effect $(C A)$ on which we focus. Last, to address the potential Nickell bias (Nickell (1981)) we follow the Arellano-Bond estimation procedure (Arellano and Bond (1991)) in which a first-difference of equation (10) is examined (hence, state fixed effects are dropped) and explanatory variables are instrumented using their lagged values.

The coefficient on $C A$ provides the expected result in both cases, supporting the patterns observed in Figure 6 during the years 1980-1986. In Column 2 ( $N R R$ case) it is positive, yet in Column 3 ( $R R$ case) it is negative. This distinction provides further clarification of the decomposition undertaken in the earlier cases. It is not the case that the observed positive effect in the $N R R$ group is relative to the $R R$ one which experienced a steep fall; rather, $N R R$ states increased their tax rates as a response to COWA regardless of $R R$ 's behavior, pointing more directly at complementarity-driven vertical tax reactions.

Departing from the case of statutory tax rates, Columns 4-6 follow the specifications of Columns 1-3 with the dependent variable (taxrates) being the baseline average tax rates. The results are similar in sign, magnitude, and precision to those obtained under the statutory cases. Specifically, the CS (common-pool) is positive (negative), and accounts for approximately $40 \%$ of the total vertical response.

\subsection{Tax disaggregation}

A key question that emerges from the benchmark analysis relates to the underlying sources. How are the CS and common-pool effects manifested? To address that we next follow a disaggregated approach to the main analysis, examining different types of state tax rates; specifically, those that comprise the baseline versions. Results appear in Table 4. We follow the benchmark specifications, as per Columns 1 and 4 of Table 3, where taxrates denote categories of either statutory or average

\footnotetext{
${ }^{36}$ Notably, the patterns in the non-COWA periods further highlight the common-trend in non-treatment years.
} 
tax rates. In the former case, we test the cases of the top corporate and income tax rates, as well as the overall sales tax rates (Columns 1-3); in the latter case, we examine the cases of the average corporate, income, and sales tax rates (Columns 4-6).

Two key observations emerge from the estimations. First, the CS channel appears to be manifested primarily via sales and income taxation. This is suggested by the results of $\gamma$ in each of the columns. Interpreting the sign and significance, rather than magnitudes, only the cases of income and sales tax rates exhibit a precisely estimated, positive outcome. This suggests that as a response to a federal tax shock, the average $N R R$ state finds it most effective to increase its tax revenues through the labor side. Second, the negative common-pool effect appears to be triggered by a decrease in both $(R R)$ capital and labor taxation. This is suggested by the estimates of $\beta$, which are constantly lower than $\gamma$ in all cases. This is consistent with the notion that under the common-pool there is a general contraction of the tax base. Unlike the case of the CS effect, in which state governments choose the source of finance, in the case of the common-pool the contraction is apparent across the board.

\section{6 g-G complementarities}

The main analysis focuses on vertical tax reactions, and the role of the CS channel within them. The latter, however, operates through the production side via complementarities or substitutabilities between the federal and state expenditures. In this sub-section we examine this link more directly, in an attempt to shed further light on the nature of the underlying mechanism of the CS-driven vertical tax response.

The treatment effect indicates how COWA collections are translated to federal expenditures. Next, we test its effect on the overall state expenditures, as well as on the more specific, main expenditure categories, namely transportation, education, health, welfare, and safety. We do so by estimating a variation of equation (10) in which taxrates is replaced by the real per capita state expenditures in each of the categories. ${ }^{37}$ We undertake a separate estimation for each case. Results appear in Table 5. Column 1 presents the case of overall state expenditures, whereas Columns 2-6 examine the more specific expenditure categories.

As noted, the CS relationship is more clearly observed in the $N R R$ states, hence similar to the previous cases our focus is on $\gamma$. The positive and precise $\gamma \mathrm{s}$ in Columns 1-3 indicate that $g$ and $G$ are, on average, complements, and that this is primarily due to $g-G$ complementarities in

\footnotetext{
${ }^{37}$ These variables enter the regressions in their natural logarithm form. This transformation enables mitigating the impact of outliers, and is enabled in this case given that there are no zero expenditures in any of the categories. Nonetheless, similar patterns are observed in case the outcome variables enter the estimated model in levels.
} 
transportation and welfare expenditures. ${ }^{38}$ This lends support to the initial motivating example, and indicates that federal expenditures related to these categories complement state public goods and thus induce increases in state expenditures. To interpret the magnitude, a one standard deviation increase in the treatment $(28 \$)$ induces an increase of approximately $1 \$$ in transportationrelated state expenditures, and an additional $1 \$$ in welfare-related state expenditures. ${ }^{39}$ In the remaining categories estimates point at an ambiguous CS relationship, where some complementarity may exist but nonetheless counteracted by some concurrent substitutability; interestingly, no clear substitutability effect is apparent in any of the categories.

\subsection{Robustness tests}

To this point we presented the benchmark results on $\beta$ and $\gamma$. In this sub-section we undertake some robustness checks to examine whether the baseline patterns are robust to various modifications. Specifically, we test additional specifications, sample restrictions, and resource abundance thresholds, as well as undertake placebo tests to further motivate the role of COWA in our results.

\subsubsection{Specifications, state divisions, and sample restrictions}

The baseline specification, as per Column 1 of Table 3, followed the specification of equation (10) due to the difference in differences framework that, as noted, maintains consistency with condition (8). We start by testing the robustness of the main results to adopting a framework that examines the difference in differences in the changes in the dependent variable. We do so by adding a lagged dependent variable to the specification. ${ }^{40}$ To address the potential Nickell bias (Nickell (1981)), we follow the previously outlined Arellano-Bond estimation procedure (Arellano and Bond (1991)). Results appear in Column 1 of Table 6. The estimated $\gamma$ and $\beta$ indicate that the main results are robust to this specification.

Second, the baseline analysis examines the sample period of 1963-2007. One concern is that the relatively long pre-period may affect the extent to which the null hypothesis is rejected. We address this in two ways. First, we consider a shorter time period; specifically, we limit the preevent and post-event periods to 10 years, hence restricting the sample to the overall period of 1970-1996. Second, following Bertrand, Duflo, and Mullainathan (2004), we collapse the sample

\footnotetext{
${ }^{38}$ This gains further support via the previously noted evidence (provided in the Appendix) on the translation of COWA collections to federal expenditures in these categories.

${ }^{39}$ Notably, this presents a lower-bound estimate. As noted, the treatment effect excludes federal expenditure categories that are expected to induce mechanic complementarities with state expenditures (i.e. matching grants). An increase in $C A$ may therefore induce further CS-driven increases in $g$ via this mechanic, excluded channel.

${ }^{40}$ This specification is equivalent to one in which the dependent variable is the rate of change between period $t-1$ and $t$.
} 
into three periods that represent the averages of the pre-treatment, treatment, and post-treatment time intervals. Results appear in Columns 2 and 3 of Table 6, respectively. Both cases indicate that the sign, precision, and relative magnitude of $\gamma$ are robust to these modifications.

Third, the benchmark results are dependent on the division of states into the two groups. The division is motivated by the model, but is specific to the case of having no resource income in COWAyears. To test whether the results are division-specific, we consider two different divisions. In the first, the $N R R$ group includes all states that had no resource income over the whole sample period, 1963-2007, with the $R R$ group accounting for the balance. In the second, the $R R$ group includes the 8 states with the highest average share of severance tax income in total tax income during our sample period, as presented in Figure 3, with the $N R R$ group accounting for the balance. The list of states under each division is presented in the Appendix. The results appear in Columns 4 and 5 of Table 6 . In both cases the estimated $\gamma$ and $\beta$ exhibit the same characteristics as those estimated in the benchmark case, indicating that the main results are robust to these changes. Interestingly, the magnitude of the common-pool effect increases in the second case, due to the composition of the $R R$ group (which unlike the baseline division, includes states with large resource endowments only); in this case, the CS effect accounts for approximately $29 \%$ of the vertical response.

Fourth, we test the case where 1980 is excluded from the sample. As noted, the $F^{i}$ measure is provided by the U.S. Census starting in 1981; its expansion to 1980 was done manually, and required additional assumptions. To test the robustness of the main results to this expansion, in Column 6 of Table 6 we follow the baseline case (Column 1 of Table 3), with 1980 excluded from the sample. The estimated $\gamma$ and $\beta$ are qualitatively and quantitatively similar to those estimated under the complete sample period.

Last, we examine the case where the COWA tax collections are assumed to be equally distributed across the nation. As noted, the constructed treatment, $C A$, implicitly assumes that the COWA revenues were allocated to states based on the relative allocations of other federal expenditures. Testing the robustness of the results to this approach, we next assume that these revenues were allocated equally on per capita terms. Hence, $C A_{i, t}$ in this case is $C O W A_{t} * \frac{P o p_{i, t}}{P o p_{n, t}}$, where the numerator is state $(i)$ population, and the denominator is the national $(n)$ population, both in year $t$. The results in Column 7 of Table 6 indicate that this alternative allocative rule yields similar patterns.

\subsubsection{Placebo tests}

One concern that may arise from the empirical analysis lies in its relation to the oil price. Recall that the variation in COWA tax collections are primarily based on variation in the price of oil. 
This suggests that the tax reactions observed may have represented responses to oil price changes rather than to COWA shocks. This was addressed in the analysis in various ways, one of which was via the time fixed effects that captured the downward trend in the oil price during COWA-years. Nonetheless, the concern remains applicable to some extent in case, for instance, some oil-related effects from non-COWA-years are persistent.

To address this using a different approach we undertake some placebo tests. As Figure 1 illustrates, the oil price was decreasing strongly starting in 1981, and throughout the COWA-years. In the preceding decade, however, the trend was largely opposite; starting in 1972, the oil price rose steeply and continuously until peaking in 1980. Hence, the period of 1972-1979 represents a counterfactual where the trend in the oil price was largely equivalent to the one in COWA-years in absolute value, yet there were no COWA collections.

We therefore focus next on this period. Given that during these years the oil price effect is applicable whereas COWA is not, the hypothesis is that if no tax reactions are observed in this placebo period then the ones estimated in the main analysis are not a result of changes in the oil price, strengthening the focus on COWA. To test this hypothesis, we follow the same methodology used in the main analysis, with some modifications in the treatment effect. Specifically, the international price of crude oil enters in lieu of $C O W A$ in equation (9), the $F_{t}^{i}$ for the treatment period is constructed similar to the way it was constructed for 1980, with the treatment period being 1972-1979. This provides a measure of the oil-price-driven federal expenditures by state, during the placebo period. We denote this placebo treatment as pre $-C A$.

Results appear in Table 7. Each column mimics the baseline Column 1 of Table 1, under three modifications. First, the treatment is pre $-C A$. Second, the period examined is 1972-1979. Third, the state division applies to the 1972-1979 period (rather than 1980-1986); this means that the $N R R$ group now includes all states that had no resource income during these years, with the $R R$ group representing the remaining states. This case is presented in Column 1. The same is done in Column 2 only under the stricter state division, where the $N R R$ group includes all states that had no resource income during all sample years (similar to Column 4 of Table 6). Last, Column 3 does the same as well yet under the state division in which the $R R$ group includes the 8 most resource rich states (similar to Column 5 of Table 6 ). The estimated $\beta$ and $\gamma$ in all cases are non-significant, having a near-zero magnitude. The patterns observed during COWA-years do not apply to the preceding years, despite the steep change in the oil price, hence emphasizing the role of COWA in driving the main patterns observed. 


\section{Conclusion}

Why do state tax rates react to federal tax shocks? This question is central to understanding vertical fiscal reactions - an issue that stands at the heart of fiscal federalism. Previous theoretical studies focused primarily on the standard common-pool problem, while remaining agnostic about having potential state-federal CS relationships. However, when a federal tax shock occurs, states may change their tax rates due to both erosion of their tax base, and complementarity or substitutability between their public goods and those of the federal government. In this paper we focused on the latter (CS) channel, making a first attempt to estimate its sign, magnitude, and relative importance in vertical fiscal interactions.

First, we examined the channel's potential importance analytically, through a generic federalism model of vertical fiscal reactions. The model showed that, all else equal, the sign and magnitude of the $g-G$ CS channel may determine the sign of the vertical tax reaction: as a response to an increase in the federal tax rate, states will increase their own tax rates if the public goods supplied by the two government levels are sufficiently complementary. In case this condition is not met, states will adjust their tax rates in an opposite direction to the change in the federal one, provided that the common-pool effect is negative.

In addition, the analytical framework showed that a design where the federal tax is over an immobile tax base allows to distinguish between the CS and common-pool channels. This is enabled because a federal tax increase leads to a vertical tax reaction composed of both the common-pool and CS channels in states rich in the immobile factor, yet at the same time also leads to a reaction driven only by the CS channel in states that lack the immobile input, since the immobile tax base confines its erosion to the states where it is located.

Motivated by the analytical setting, we exploited a quasi-natural experiment that follows that design: the 1980 Crude Oil Windfall Act. This act imposed an excise tax over the sale of crude oil that affected the income of American oil companies. Given the immobility of oil production, this act affected the tax base of oil rich states only, from which the federal government collected approximately $80 \$$ billion over a period of 7 years. Employing a U.S. state-level panel covering the period of 1963-2007, we examined the states' heterogeneous tax reactions to these federal tax shocks. We did so by following a difference-in-differences approach, which exploited a treatment effect that captured the COWA-driven federal expenditures in each state. The fiscal reactions of the resource poor states to this treatment were attributed to the CS channel. The identification strategy was based on the plausibly exogenous nature of the treatment (COWA-based) and treatment group (subset of states with geographically-based natural endowments), as well as on a common-trend in 
non-treatment years.

Results from the empirical analysis indicated that the CS channel takes a considerable share in the overall vertical interactions - approximately $38 \%$ in our baseline estimates. In addition, they showed that the resource-poor states' tax reactions comove with the federal tax shocks, pointing at complementarities between state and federal public goods that is manifested primarily via changes in states' sales and income taxation. The latter, thus, suggested that a stronger reliance on labor taxation may lead to larger dominance of the CS effect in the overall vertical fiscal reaction. In addition, a more direct examination of the expenditure-based CS relationship indicated that $g$ and $G$ are on average complements, driven primarily by complementarities in expenditures related to transportation and welfare. Last, the results also indicated that the common-pool channel is negative: a greater erosion of the tax base leads to greater decreases in state tax rates.

The paper has, thus, shed new light on the sources of vertical fiscal reactions by providing evidence on the magnitude, sources, and relative importance of the CS channel within the scope of fiscal federalism, through a specific quasi-natural experiment that enabled its identification. This specificity, however, came at a cost as the results are confined to oil-related fiscal shocks and top-to-bottom externalities. Future research may look into scenarios that allow for cross-tax complementarities and bottom-to-top dynamics, as well as for the examination of different time periods and federations, as data become available. 


\section{Online Appendix}

\section{A Additional Theoretical Results}

In this appendix, we give specific functional forms to the generic theoretical framework presented in the main text of the paper and apply it to three specific tax scenarios. In particular, consistent with the empirical section, we assume that states differ in their abundance of natural resources, and analyze the implications for the response of the state capital-income, corporate and sales tax rates to a change in the federal severance tax rate.

We suppose that the federal government charges firms that operate in the extractive industry (sector $x$ ) a tax rate $T_{n}$ on the level of production of natural resources; that is,

$$
T=T_{n} \text { and } B=\sum_{v=1}^{Z} y_{x v} ;
$$

where $y_{x v} \geq 0$ represents the natural-resource industry's production level in state $v$. We also consider the following specific functional forms:

$$
v\left(c_{s}\right)=\ln c_{s}
$$

and

$$
\Gamma\left(g_{s}, G\right)=\left(g_{s}^{\sigma}+G^{\sigma}\right)^{1 / \sigma} .
$$

The value of the elasticity parameter $\sigma$ lies within the interval $(-\infty, 1]$. When $\sigma$ equals $-\infty$ and 1 , state and federal public goods are perfect complements and perfect substitutes, respectively.

Since two of the taxes studied affect factors of production, we need to introduce into the framework a production side that employs capital and natural resources as inputs. Here, the proposed structure is reminiscent of the one constructed in Perez-Sebastian, Raveh, and Reingewertz (2016) yet focuses on a different federal tax and includes the response of the firm's demand for capital to taxation. Individuals and the natural-resource input are immobile. However, we allow the capital input to freely move across states. Following the tradition of Keen and Kotsogiannis (2002) and Zodrow and Mieszkowski (1986), this mobility of capital adds to the setting elements of horizontal tax competition when we consider capital taxation. ${ }^{41}$ Each individual owns a fixed amount of capital $k$ that can be supplied to the production activity in any of the states. In return, consumers obtain an interest rate $r_{s}$ per unit of capital.

We further assume that profit-maximizing firms operate under perfect competition in one of two industries: consumption-goods production (sector $m$ ), and extraction of raw materials from the earth (i.e., sector $x$ ). Sector $m$ is the numeraire. For simplicity, consumption goods can be traded among different states, whereas the output of the extractive enterprises is fully exported abroad. Each firm that manufactures the consumption good in state $s$ is owned by a consumer that resides in that state. Firms that operate in the extracted industry are, on the other hand, owned by all state residents who have equal shares of the natural input.

In state $s$, consumption-goods manufacturers generate output $\left(y_{m s}\right)$ using capital $\left(k_{m s}\right)$ according to:

$$
y_{m s}=k_{m s}^{\alpha}
$$

\footnotetext{
${ }^{41}$ Several studies have shown that this feature arises in a vast array of economies such as the U.S., Russia, China, and others. See Wilson and Wildasin (2004) for a survey. Notably, we assume that the fiscal competition is manifested via tax rates; however, it may be undertaken via other instruments as well, including expenditure, especially as the latter is affected by federal taxation. Nonetheless, following Wildasin (1988), we assume that the number of states is sufficiently large so that Nash equilibria in tax rates and expenditures coincide.
} 
where $\alpha \in(0,1)$, that is, the production function displays diminishing marginal returns over the capital input. Firms in the extractive business produce output combining capital and natural resources according to

$$
y_{x s}=k_{x s}^{\alpha} n_{s}^{1-\alpha}
$$

where $n_{s}$ is the stock of natural resources available in state $s$.

Consider now that state $s$ can impose capital-income, corporate and sales tax rates; denoted by $t_{k s}, t_{\pi s}$ and $t_{c s}$, respectively. Because capital freely moves across states and under the small-economy assumption, state governments take as given the net-of-taxes return to capital $(\rho)$. Therefore, it must be the case that

$$
\rho=r_{s}\left(1-t_{k s}\right) \text { for all } s=1, \ldots, Z .
$$

Incorporating this into the first order conditions of the firm's profit-maximization problem obtains the following demand functions for capital in sectors $m$ and $x$, respectively:

$$
k_{m s}=\left[\frac{\alpha}{\rho}\left(1-t_{k s}\right)\right]^{\frac{1}{1-\alpha}}
$$

and

$$
k_{x s}=\left[\frac{\alpha}{\rho}\left(p-T_{n}\right)\left(1-t_{k s}\right)\right]^{\frac{1}{1-\alpha}} n_{s} ;
$$

where $p$ is the unit price of the $x$-sector's output. The last two functions also depict a horizontal competition among states, and imply that a state that charges a lower tax rate $t_{k s}$ will attract capital, and will end up with a larger per capita stock in its production process.

Another implication of the profit-maximizing behavior is that the profits that a firm in sector $m$ makes $\left(\pi_{m s}\right)$ equal a fraction $1-\alpha$ of their output. Given the ownership structure in sector $x$, we treat the rents from the exploitation of natural resources as profits, and then, profits in the extractive industry $\left(\pi_{x s}\right)$ also equal a fraction $1-\alpha$ of the value of output. Combining this with expressions (16), (17), (19) and (20) obtains

$$
\pi_{m s}=(1-\alpha)\left[\frac{\alpha}{\rho}\left(1-t_{k s}\right)\right]^{\frac{\alpha}{1-\alpha}}
$$

and

$$
\pi_{x s}=(1-\alpha)\left[\frac{\alpha}{\rho}\left(1-t_{k s}\right)\right]^{\frac{\alpha}{1-\alpha}} n_{s}\left(p-T_{n}\right)^{\frac{1}{1-\alpha}} .
$$

As explained in the main text, our benevolent policy-maker in state $s$ chooses the tax rates to solve problem (3) subject to (1), (2) and (4) internalizing the domestic-firms' behavior. With the specific functional forms and tax schedules considered, this problem can be written as:

$$
\max _{\left\{t_{k s}, t_{\pi s}, t_{c s}\right\}}\left\{u\left(c_{s}, g_{s}, G\right)=\ln c_{s}+\left(g_{s}^{\sigma}+G^{\sigma}\right)^{1 / \sigma}\right\}
$$

subject to

$$
\begin{gathered}
g_{s}=t_{k s} r_{s} k_{s}+t_{\pi s} \pi_{s}+t_{c s} c_{s}, \\
G=T_{n} \bar{n}, \text { with } \bar{n}=\frac{1}{Z} \sum_{v=1}^{Z} n_{v},
\end{gathered}
$$




$$
\begin{gathered}
c_{s}=\frac{1}{1+t_{c s}}\left[\left(1-t_{\pi s}\right) \pi_{s}+\rho k\right], \\
\quad \text { and (19) to }(22) ;
\end{gathered}
$$

where $k_{s}=k_{m s}+k_{x s}$ and $\pi_{s}=\pi_{m s}+\pi_{x s}$.

Finally, in order to close the model, we need the following market clearing conditions for capital and goods produced by firms, respectively:

$$
\begin{gathered}
k=\frac{1}{Z} \sum_{v=1}^{Z} k_{v}, \\
\sum_{v=1}^{Z}\left(y_{m v}+p y_{x v}\right)=\sum_{v=1}^{Z}\left(c_{s}+g_{s}+G\right) .
\end{gathered}
$$

These two conditions allow for trade in capital and the two private goods across states. Remember that we assume that the extractive industry exports abroad all output and that the number of agents in the economy is a mass of size one.

Next, we analyze in separate subsections the impact of the federal severance tax rate $T_{n}$ on each of the three different state tax rates considered above.

\section{A.1 Capital-income taxes}

Suppose that the government in state $s$ raises revenues only from capital taxes at rate $t_{k s}$. This means that $t_{\pi s}=t_{c s}=0, t=t_{k s}$ and $b=r_{s} k_{s}$. We now ask the question: how do changes in $T_{n}$ affect the optimal $t_{k s}$ ? The FOC to problem (23) with respect to $t_{k s}$ yields:

$$
\begin{aligned}
\frac{\alpha /(1-\alpha)}{\left(1+\frac{\rho k}{c-\rho k}\right)\left(1-t_{k s}\right)}= & {\left[1+\left(\frac{T_{n} \bar{n}}{t_{k s} r_{s} k_{s}}\right)^{\sigma}\right]^{\frac{1-\sigma}{\sigma}} * } \\
& \alpha\left(\frac{\alpha}{\rho}\right)^{\frac{\alpha}{1-\alpha}}\left[1+n_{s}\left(p-T_{n}\right)^{\frac{1}{1-\alpha}}\right]\left(1-t_{k s}\right)^{\frac{\alpha}{1-\alpha}}\left(1-\frac{t_{k s}}{1-\alpha}\right) .
\end{aligned}
$$

The LHS of (29) represents the marginal utility of private-good consumption $(M U c)$, and the right hand side (RHS) gives the marginal utility of state public-good consumption ( $M U g$ ), both with respect to the tax rate $t_{k s}$. Looking at the RHS in more detail, it equals the CS term (above) times the marginal revenue (below).

Combining equations (26) and (29) the FOC simplifies to

$$
\left[1+\left(\frac{T_{n} \bar{n}}{t_{k s} r_{s} k_{s}}\right)^{\sigma}\right]^{\frac{1-\sigma}{\sigma}}\left(1-\frac{t_{k s}}{1-\alpha}\right)\left\{(1-\alpha)\left[\frac{\alpha}{\rho}\left(1-t_{k s}\right)\right]^{\frac{\alpha}{1-\alpha}}\left[1+n_{s}\left(p-T_{n}\right)^{\frac{1}{1-\alpha}}\right]+\rho k\right\}=1 .
$$

The main difference between the last two expressions is that, in the latter, some of the terms that compose the marginal utility and the marginal revenue cancel out, eliminating the ambiguity of the common-pool effect. To see this, suppose that $\sigma=1$ in (30), so that the CS term becomes one. The remaining terms are all associated to the common-pool mechanism, and an increase in $T_{n}$ triggers a reduction in $t_{k s}$. That is, the common-pool effect is negative.

The sign of the CS channel can be deduced when we consider the opposite case, $\sigma=-\infty$. 
Now, the two public goods are perfect complements and the optimal decision equalizes $T_{n} \bar{n}$ to $t_{k s} r_{s} k_{s}$ (or $G=g_{s}$ ). Even though we can deduce from (19) and (20) that the tax base falls if the capital-income tax rate rises, the supply of the state public good $g_{s}$ increases with $t_{k s}$, and then, the derivative of $t_{k s}$ with respect to $T_{n}$ is positive. Put differently, as both public goods become more complementary, $g_{s}$ follows the change in $G$ more closely and always in the same direction.

Hence, the sign of $d t_{k s} / d T_{n}$ depends on which effect dominates: if the CS effect is sufficiently strong - i.e., $\sigma$ small enough - this derivative will be positive; otherwise, it will be negative. ${ }^{42}$

Mathematically, we can apply the implicit function theorem to FOC (30) to obtain:

$$
\frac{d t_{k s}}{d T_{n}}=\frac{\frac{(1-\sigma)\left(\frac{G}{g_{s}}\right)^{\sigma-1}}{\left[1+\left(\frac{G}{g_{s}}\right)^{\sigma}\right]} \frac{\bar{n}-\frac{G}{g_{s}} t_{k s} \frac{\partial r_{s} k_{s}}{\partial T_{n}}}{g_{s}}\left(\pi_{s}+\rho k\right)-\left[\frac{\alpha}{\rho}\left(1-t_{k s}\right)\left(p-T_{n}\right)\right]^{\frac{\alpha}{1-\alpha}} n_{s}}{\left(1-\frac{t_{k s}}{1-\alpha}\right)^{-1}\left[1+\left(\frac{G}{g_{s}}\right)^{\sigma}\right]^{\frac{\sigma-1}{\sigma}}\left[-\frac{\partial \mathrm{FOC}\left(t_{k s}\right)}{\partial t_{k s}}\right]} .
$$

where

$$
\frac{\partial r_{s} k_{s}}{\partial T_{n}}=-\frac{\alpha}{1-\alpha}\left[\frac{\alpha\left(1-t_{k s}\right)}{\rho}\left(p-T_{n}\right)\right]^{\frac{\alpha}{1-\alpha}} n_{s}<0 .
$$

The last derivative is the result of using (19), (20) and the optimality condition that says that $r_{s}$ must equal the value of the marginal product of capital.

The empirically supported value of the share of capital $\alpha$ is around 0.34 . Hence, it is sensible to think that $t_{k s}<1-\alpha$. Which implies that the denominator of (31) is positive, because the second derivative of the objective function with respect to the choice variable has to be always negative (i.e., $\left.\partial \mathrm{FOC}\left(t_{k s}\right) / \partial t_{k s}<0\right)$. Hence, the sign of $d t_{k s} / d T_{n}$ is determined by the numerator.

The first and second summands in the numerator of (31) correspond to the CS and common-pool channels, respectively. When $\sigma=1$, the first summand becomes zero and only the common-pooleffect term remains, which has a negative impact since $p>T_{n}$. For $\sigma$ smaller than zero, the CS channel is positive. Furthermore, if state $s$ does not have natural resources then $n_{s}$ equals zero and the CS effect fully drives the effect of $T_{n}$ on $t_{k s}$.

\section{A.2 Corporate taxes}

Next, we study the impact of a change in the federal severance tax rate $T_{n}$ on the state corporate tax rate $t_{\pi s}$, assuming that this is the only source of revenue for state $s$. That is, $t_{k s}=t_{c s}=0$, $t=t_{\pi s}$ and $b=\pi_{s}$. The FOC of problem (23) now delivers:

$$
\left[1+\left(\frac{T_{n} \bar{n}}{t_{\pi s} \pi_{s}}\right)^{\sigma}\right]^{\frac{1-\sigma}{\sigma}}\left[\left(1-t_{\pi s}\right) \pi_{s}+\rho k\right]=1 .
$$

\footnotetext{
${ }^{42} \mathrm{~A}$ similar result is obtained if we look at the impact of the natural-resource endowment on the state tax rate. The LHS of equation (30) can be divided into three terms. The first one, in squared brackets, captures the CS channel. The second one, in parenthesis, collects what is left of the marginal revenue. The third one, in curly brackets, proxies the marginal utility of consumption. If we only look at the marginal revenue and marginal utility terms, an increase in $n_{s}$ requires an increase in $t_{k s}$ to maintain the capital tax base at the same value. If on the other hand, we focus on the CS term, the increase in the natural-resource stock induces a higher capital demand, and then, the capital-income tax rate needs to fall to maintain the state public good at the desired level. Therefore, the sigh of $d t_{k s} / d n_{s}$ depends on which effect dominates. Clearly, as both public goods become more complementary (lower $\sigma$ ), a negative sign becomes more likely. This result is also obtained with the other two tax rates considered in the Appendix.
} 
Employing (21), (22), and the implicit function theorem, the impact of a change in the federal severance tax rate on $t_{\pi s}$ is given by

$$
\frac{d t_{\pi s}}{d T_{n}}=\frac{\frac{(1-\sigma)\left(\frac{G}{g_{s}}\right)^{\sigma-1}}{\left[1+\left(\frac{G}{g_{s}}\right)^{\sigma}\right]} \frac{\bar{n}-\frac{G}{g_{s}} t_{\pi s} \frac{\partial \pi_{s}}{g_{s}}}{g_{s}}\left[\left(1-t_{\pi s}\right) \pi_{s}+\rho k\right]-\left(1-t_{\pi s}\right)\left[\frac{\alpha}{\rho}\left(p-T_{n}\right)\right]^{\frac{\alpha}{1-\alpha}} n_{s}}{\left[1+\left(\frac{G}{g_{s}}\right)^{\sigma}\right]^{\frac{\sigma-1}{\sigma}}\left[-\frac{\partial \mathrm{FOC}\left(t_{\pi s}\right)}{\partial t_{\pi s}}\right]}
$$

where

$$
\frac{\partial \pi_{s}}{\partial T_{n}}=-\left[\frac{\alpha}{\rho}\left(p-T_{n}\right)\right]^{\frac{\alpha}{1-\alpha}} n_{s}<0 .
$$

Because $\partial \mathrm{FOC}\left(t_{\pi s}\right) / \partial t_{\pi s}<0$, the denominator is positive. The CS and common-pool effects - captured by the first and second summands in the numerator - are again positive and negative, respectively. Hence, as in the case of capital-income taxation, the sign of the derivative of $t_{\pi s}$ with respect to $T_{n}$ is positive if the CS channel dominates, and negative if the common-pool mechanism is the predominant one. It also becomes obvious that, if $n_{s}$ equals zero, this derivative is fully driven by CS forces.

\section{A.3 Sales taxes}

Finally, we analyze the effect of a variation in $T_{n}$ on $t_{c s}$, supposing that this is the only source of revenue in state $s$ (i.e., $t_{k s}=t_{\pi s}=0, t=t_{c s}$ and $b=c_{s}$ ). The FOC is now:

$$
\left[1+\left(\frac{T_{n} \bar{n}}{t_{c s} c_{s}}\right)^{\sigma}\right]^{\frac{1-\sigma}{\sigma}} \frac{1}{1-t_{c s}}\left(\pi_{s}+\rho k\right)=1 .
$$

And then

$$
\frac{d t_{c s}}{d T_{n}}=\frac{\frac{(1-\sigma)\left(\frac{G}{g_{s}}\right)^{\sigma-1}}{\left[1+\left(\frac{G}{g_{s}}\right)^{\sigma}\right]} \frac{\bar{n}-\frac{G}{g_{s}} t_{c s} \frac{\partial c_{s}}{\partial T_{n}}}{g_{s}}\left(\pi_{s}+\rho k\right)-\left[\frac{\alpha}{\rho}\left(p-T_{n}\right)\right]^{\frac{\alpha}{1-\alpha}} n_{s}}{\left(1+t_{c s}\right)\left[1+\left(\frac{G}{g_{s}}\right)^{\sigma}\right]^{\frac{\sigma-1}{\sigma}}\left[-\frac{\partial \mathrm{FOC}\left(t_{\pi s}\right)}{\partial t_{\pi s}}\right]}
$$

where

$$
\frac{\partial c_{s}}{\partial T_{n}}=-\frac{1}{1-t_{c s}}\left[\frac{\alpha}{\rho}\left(p-T_{n}\right)\right]^{\frac{\alpha}{1-\alpha}} n_{s}<0
$$

Regarding the sign of the common-pool and CS effects, it is straightforward to show that, once more, the common-pool effect is negative and the CS effect is positive. Again, if $n_{s}=0$, the change in the state tax rate exclusively depends on the CS mechanism.

\section{B Data}

We use an annual-based state-level panel that covers the 50 U.S. states over the period of 19632007. Unless otherwise specified, variables are based on data from the U.S. Bureau of Economic Analysis and the U.S. Census Bureau. Descriptive statistics for all variables appear in Table 1 for the general sample, and in the Appendix Table A4 for the separate $R R$ and $N R R$ groups (under the baseline division).

Variable definitions 
Real annual COWA collections: The annual receipts from the 1980 Crude Oil Windfall Act (million \$) normalized by U.S. GDP, both in 2013 prices (Source: U.S. Office of Management and Budget). Positive collections were made only in the years 1980-1986. Annual collections are graphed in Figure 2.

Real per capita federal expenditures by state: Real per capita federal government expenditures in each state, net of federal transfers to states and direct payments to individuals in each state, in 1981-1986. This was expanded to 1980 using the equivalent (expenditure and population) measures at the U.S. level, based on the assumption that in per capita terms these federal expenditures are distributed equally across the nation.

Real per capita GSP: Real per capita Gross State Product.

Annual rate of change in real per capita capital stock: The annual rate of change in real per capita capital stock (Source: Garofalo and Yamarik (2002) for the pre-1997 years; post-1996 figures are based on their extension of their original data, available on the second author's homepage).

Annual rate of change in population: The annual rate of change in state population.

Statutory tax rates (baseline, corporate, income, sales): Top state corporate and income tax rates, and state sales tax rates. The baseline version is the weighted average of these corporate, income, and sales statutory tax rates, with the weights being the share of the tax revenues of each in their sum, in the initial year (1963) (Source: the World Tax Database at the University of Michigan, and the U.S. Tax Foundation).

Average tax rates (baseline, corporate, income, sales): State tax revenues (in the relevant category) normalized by GSP. The baseline version is the weighted average of the corporate, income, and sales average tax rates, with the weights being the share of the tax revenues of each in states' total revenues in the initial year (1963).

Real per capita general government expenditure (or in the following sub-categories: education, health, transportation, public safety, public welfare - used in Table A2): Real per capita state general government expenditure (or in the corresponding sub-category).

Real per capita transfers: Real per capita transfers from the federal to states' governments.

\section{State divisions}

Benchmark division: Resource poor states' group (NRR) includes all states with no severance tax collections during COWA-years (1980-1986). These include: Arizona, Connecticut, Delaware, Georgia, Hawaii, Illinois, Iowa, Maine, Maryland, Massachusetts, Nevada, New Jersey, New York, Pennsylvania, Rhode Island, South Carolina, Vermont, and West Virginia. The remaining states are included under the resource rich states' group (RR). Unless otherwise specified, this division is used, including in the relevant figures.

NRR-no-resources, all sample, division: Resource poor states' group (NRR) includes all states with no severance tax collections during all sample years (1963-2007). These include: Connecticut, Delaware, Georgia, Hawaii, Iowa, Maine, Maryland, Massachusetts, New Jersey, New York, Pennsylvania, Rhode Island, South Carolina, and Vermont. The remaining states are included under the resource rich states' group (RR). This division is used in Regression 4 of Table 6, and Regression 2 of Table 7.

$R R$-dominance division: Resource rich states' group (RR) includes the 8 states with the highest average share of severance tax income in total tax income during our sample period, as presented in Figure 3. These include: Alaska, Louisiana, Montana, North Dakota, New Mexico, Oklahoma, Texas, and Wyoming. The remaining states are included under the resource poor states' group (NRR). This division is used in Regression 5 of Table 6, and Regression 3 of Table 7.

NRR-no-resources, pre-COWA-years, division: Resource poor states' group (NRR) includes all states with no severance tax collections during pre-COWA-years (1972-1979). These include: Arizona, Connecticut, Delaware, Georgia, Hawaii, Illinois, Iowa, Maine, Maryland, Massachusetts, Nevada, New Jersey, New York, Pennsylvania, Rhode Island, South Carolina, Vermont, and West Virginia. The remaining states are included under the resource rich states' group (RR). This division is used in Regression 1 of Table 7. 


\section{COWA and Federal Spending}

In this section we undertake a brief, descriptive, exploration of the federal expenditure categories affected by COWA, to realize whether tax receipts from COWA were translated, at least to some extent, to spending at the federal level. As mentioned previously, the general objective of the federal administration was to use the revenues collected from COWA to assist low-income households, invest in mass transit, and explore new energy sources. Let us test whether this was indeed the case; specifically, whether COWA receipts are associated with federal spending in these categories. To do so, we estimate the following simple time-series model for year $t$ :

$$
\text { spending }_{t}=\alpha+\beta(\text { net_receipts })_{t}+\gamma(C O W A)_{t}+\delta(g d p p c)_{t}+\zeta(\text { net_spending })_{t}+y e a r+\epsilon_{t}
$$

where spending denotes one of the nine main federal spending functions: energy, regional development, transportation, income and social security, housing, education, health, national defense, and 'others'. ${ }^{43}$ COW $A$ represents the plausibly exogenous annual federal tax collections derived from COWA, net_receipts denotes the federal revenues net of $C O W A, g d p p c$ is per capita U.S. GDP, net_spending is the federal spending net of spending (i.e. net of federal spending in the category examined), and year is a time trend. ${ }^{44}$ The period covered is 1963-2007, consistent with the one covered in the main analysis. All measures are in real terms. Data is from the U.S. Office of Management and Budget. Descriptive statistics are provided in Table A3.

Our interest lies in the parameter $\gamma$, which measures whether the COWA tax revenues from 1980 to 1986 affected the spending category, controlling for other federal receipts and expenditures, general income level, and a time trend. Results appear in Table A2. The sign and significance of $\gamma$ in the various cases indicate that COWA tax revenues are positively related to federal spending on energy, regional development, transportation, and income and social security, but do not bear a notable relation with the remaining spending categories. The apparent match between the affected categories and those targeted upon enactment of the act suggests that the objectives of the federal administration were met to some extent; importantly, they indicate that the COWA tax receipts were indeed translated, to some degree, to federal public spending.

\footnotetext{
${ }^{43}$ 'Others' is an aggregate of the remaining relatively smaller functions that include: International affairs, Science, Agriculture, Justice, General Government, and Allowances.

${ }^{44}$ Given the time-series framework, one concern is that our measures are non-stationary. Note, however, that the residuals from all the following estimations appear stationary, via Augmented Dickey-Fuller tests, hence not rejecting the possibility of cointegration.
} 


\section{References}

Acemoglu, D., A. Finkelstein, and M. Notowidigdo (2013): "Income and Health Spending: Evidence from Oil Price Shocks," Review of Economics and Statistics, 95(4), 1079-1095.

Arellano, B., and S. Bond (1991): "Some Tests of Specification for Panel Data: Monte Carlo Evidence and an Application to Employment Equations," Review of Economic Studies, 58(2), $277-297$.

Berry, C. (2008): "Piling On: Multilevel Government and the Fiscal Common-Pool," American Journal of Political Science, 52(4), 802-820.

Bertrand, M., E. Duflo, and S. Mullainathan (2004): "How much should we trust differences-in-differences estimates?," Quarterly Journal of Economics, 119, 249-275.

Besley, T., And H. S. Rosen (1998): "Vertical Externalities in Tax Setting: Evidence from Gasoline and Cigarettes," Journal of Public Economics, 70, 383-398.

Blochliger, H., and C. Charbit (2008): "Fiscal Equalisation," OECD Economic Studies, 44.

Boadway, R. (2006): "Natural Resource Shocks and the Federal System: Boon and Curse?," Fiscal Federalism and the Future of Canada Conference Proceedings, Institute of Intergovernmental Relations.

Boadway, R., and M. Keen (1996): "Efficiency and the Optimal Direction of Federal-State Transfers," International Tax and Public Finance, 3, 137-155.

Boadway, R., M. Marchand, and M. Vigneault (1996): "The Consequences of Overlapping Tax Bases For Redistribution and Public Spending in a Federation," Journal of Public Economics, $3,453-478$.

Brennan, G., and J. Buchanan (1980): The Power to Tax: Analytical Foundations of a Fiscal Constitution. Cambridge University Press.

Cai, T., and D. Treisman (2005): "Does Competition for Capital Discipline Governments? Decentralization, Globalization, and Public Policy," American Economic Review, 95, 817-830.

Dahlby, B. (1996): "Fiscal Externalities and the Design of Intergovernmental Grants," International Tax and Public Finance, 3(3), 397-412.

Dahlby, B., And S. L. Wilson (2003): "Vertical Fiscal Externalities in a Federation," Journal of Public Economics, 87, 917-930.

Devereux, M. P., B. Lockwood, and M. Redoano (2007): "Horizontal and Vertical Indirect Tax Competition: Theory and Some Evidence From the USA," Journal of Public Economics, 91(3), 451-479.

Esteller-More, A., And A. Sole-Olle (2001): "Vertical Income Tax Externalities and Fiscal Interdependence: Evidence From the US," Regional Science and Urban Economics, 31, 247-272.

Frankel, A., And D. Romer (1999): "Does trade cause growth?," American Economic Review, 89, 379-399.

Fredriksson, P. G., and K. A. Mamum (2008): "Vertical Externalities in Cigarette Taxation: Do tax Revenues Go Up in Smoke?," Journal of Urban Economics, 64, 35-48. 
Garofalo, G., and S. Yamarik (2002): "Regional Convergence: Evidence from a New Stateby-State Capital Stock Series," Review of Economics and Statistics, 84, 316-323.

Goodspeed, J. T. (2000): "Tax Structure in a Federation," Journal of Public Economics, 75, 493-506.

Gramlich, E. (1977): "Intergovernmental Grants: A Review of the Empirical Literature," In The Political Economy of Fiscal Federalism. Ed. Wallace E. Oates. Lexington, MA: Lexington Books.

Hafer, C., And D. Landa (2007): "Public Goods in Federal Systems," Quarterly Journal of Political Science, 2, 253-275.

Hayashi, M., and R. Boadway (2001): "An Empirical Analysis of Intergovernmental Tax Interaction: The Case of Business Income Taxes in Canada," Canadian Journal of Economics, 34(2), 481-503.

Hines, R. J., And H. R. Thaler (1995): "The Flypaper Effect," Journal of Economic Perspectives, $9,217-226$.

Hoyt, W. H. (2001): "Tax Policy Coordination, Vertical Externalities, and Optimal Taxation in a System of Hierarchical Governments," Journal of Urban Economics, 50, 491-516.

Inman, R., And D. Rubinfeld (1997): "Rethinking Federalism," Journal of Economic Perspectives, 11, 43-64.

Inman, R. P. (2008): “The Flypaper Effect,” NBER Working Paper No. 14579.

James, A. (2014): "U.S. State Fiscal Policy and Natural Resources," American Economic Journal: Economic Policy, 7(3), 238-257.

Keen, M. (1998): "Vertical Tax Externalities in the Theory of Fiscal Federalism," IMF Staff Papers, 45, 454-485.

Keen, M., and C. Kotsogiannis (2002): "Does Federalism Lead to Excessively High Taxes?," American Economic Review, 92, 363-370.

Knight, B. (2002): "Endogenous Federal Grants and Crowd-Out of State Government Spending: Theory and Evidence from the Federal Highway Aid Program," American Economic Review, 92, $71-92$.

(2006): "Common Tax Pool Problems in Federal Systems," In Democratic Constitutional Design and Public Policy: Analysis and Evidence,ed.RogerCongleton and Brigitta Swedenborg. Cambridge, MA: MIT Press, 229ï£j50.

Lazzari, S. (2006): "The Crude Oil Windfall Profit Tax of the 1980s: Implications for Current Energy Policy," Congressional Research Service Report for Congress, the Library of the U.S. Congress.

Martinez-Vazquez, J., and B. Searle (2007): Fiscal Equalization: Challenges in the Design of Intergovernmental Transfers. Springer Science and Business Media.

Nickell, S. (1981): "Biases in dynamic models with fixed effects," Econometrica, 49, 1417-1426.

OAtes, W. (1972): "Fiscal Federalism," New York: Harcourt Brace Jovanovich, Academic Press. 
Olson, M. (1969): "The Principle of "Fiscal Equivalence": The Division of Responsibilities among Different Levels of Government," American Economic Review Papers and Proceedings, 59(2), 479-487.

Perez-Sebastian, F., and O. Raveh (2016): "The Natural Resource Curse and Fiscal Decentralization," American Journal of Agricultural Economics, 98(1), 212-230.

Perez-Sebastian, F., O. Raveh, and Y. Reingewertz (2016): "Heterogeneous Vertical Tax Externalities, Capital Mobility, and the Fiscal Advantage of Natural Resources," OxCarre Working Paper No. 160.

Poterba, J., and J. von Hagen (1999): "Fiscal Institutions and Fiscal Performance," Chicago: University of Chicago Press.

Qian, Y., and G. Roland (1998): "Federalism and the Soft Budget Constraint," American Economic Review, 88(5), 1143-1162.

Raven, O. (2013): "Dutch Disease, Factor Mobility, and the Alberta Effect - The Case of Federations," Canadian Journal of Economics, 46(4), 1317-1350.

Raveh, O., And A. Reshef (2016): "Capital Imports Composition, Complementarities, and the Skill Premium in Developing Countries," Journal of Development Economics, 118, 183-206.

Reingewertz, Y. (2018): "Corporate Taxes and Vertical Tax Externalities: Evidence from Narrative Federal Tax Shocks," Regional Science and Urban Economics, 68, 84-97.

Romer, D. C., and H. D. Romer (2010): "The Macroeconomic Effects of Tax Changes: Estimates Based on a New Measure of Fiscal Shocks," American Economic Review, 100, 763-801.

Smart, M. (1998): "Taxation and Deadweight Loss in a System of Intergovernmental Transfers," Canadian Journal of Economics, 31, 189-206.

Tiebout, C. (1956): "A Pure Theory of Local Government Expenditures," Journal of Political Economy, 64, 416-424.

Wildasin, E. D. (1988): "Nash Equilibria in Models of Fiscal Competition," Journal of Public Economics, 35, 229-240.

Wilson, D. J. (1999): "Theories of Tax Competition," National Tax Journal, 52, 269-304.

Wilson, D. J., And D. E. Wildasin (2004): "Capital Tax Competition: Bane or Boon," Journal of Public Economics, 88, 1065-1091.

Wilson, J. D. (2015): "Tax Competition in a Federal Setting," in Handbook of Multilevel Finance, edited by Ehtisham Ahmad and Giorgio Brosio, Edward Elgar Publishing.

Zodrow, G., and Z. Mieszkowski (1986): "Pigou, Tiebout, Property Taxation, and the Under Provision of Local Public Goods," Journal of Urban Economics, 19, 356-370. 


\begin{tabular}{|c|c|c|c|c|}
\hline & Mean & Std. Dev. & Min. & Max. \\
\hline Real per capita GSP & 31281.08 & 10951.71 & 11351.48 & 110865.7 \\
\hline Real COWA collections, 1980-1986 (Million \$) & 11176.14 & 6825.18 & 2251 & 23252 \\
\hline $\begin{array}{l}\text { Real state-specific federal expenditures per capita (net of transfers and payments to } \\
\text { individuals), 1980-1986 (Thousand \$) }\end{array}$ & 0.684 & 0.436 & 0.082 & 2.151 \\
\hline $\begin{array}{l}\text { Treatment effect (CA) -- COWA-driven real state-specific federal expenditures per } \\
\text { capita (net of transfers and payments to individuals), 1980-1986 (Thousand \$) }\end{array}$ & 0.039 & 0.028 & 0.005 & 0.146 \\
\hline Real per capita federal transfers to state governments & 573.27 & 515.50 & 27.21 & 3916.77 \\
\hline Real per capita state government expenditure & 3496.01 & 1912.14 & 852.14 & 17485.54 \\
\hline Annual rate of change in real per capita capital stock & 0.02 & 0.03 & -0.08 & 0.42 \\
\hline Annual rate of change in population & 0.01 & 0.01 & -0.06 & 0.10 \\
\hline Baseline statutory tax rates & 0.05 & 0.02 & 0 & 0.14 \\
\hline Baseline average tax rates & 0.02 & 0.007 & 0.005 & 0.05 \\
\hline Average corporate tax rates & 0.003 & 0.003 & 0 & 0.04 \\
\hline Average income tax rates & 0.01 & 0.009 & 0 & 0.04 \\
\hline Average sales tax rates & 0.03 & 0.01 & 0.003 & 0.05 \\
\hline Top corporate tax rate & 0.06 & 0.03 & 0 & 0.12 \\
\hline Top income tax rate & 0.05 & 0.04 & 0 & 0.2 \\
\hline Sales tax rate (statutory) & 0.04 & 0.02 & 0 & 0.08 \\
\hline Real per capita state government expenditure on education & 1128.97 & 524.92 & 138.54 & 3871.36 \\
\hline Real per capita state government expenditure on health & 99.98 & 83.67 & 3.97 & 645.35 \\
\hline Real per capita state government expenditure on transportation & 369.13 & 198.79 & 110.40 & 2192.85 \\
\hline Real per capita state government expenditure on public welfare & 608.86 & 435.84 & 43.23 & 2549.25 \\
\hline Real per capita state government expenditure on public safety & 74.01 & 73.11 & 2 & 463.52 \\
\hline
\end{tabular}


Table 2: Total difference in differences, State tax rates and COWA, 1963-2007

\begin{tabular}{c|cc}
\hline \hline \multirow{2}{*}{ Dependent variable: } & $(1)$ & $(2)$ \\
\cline { 2 - 3 } CA $*$ RR $(t-1)$ & Baseline statutory tax rates, time $t$ & Baseline average tax rates, time $t$ \\
\hline CA & $-0.1086^{* * *}$ & $-0.069^{* * *}$ \\
& $(0.03)$ & $(0.02)$ \\
& $0.067^{* *}$ & $0.048^{* *}$ \\
Controls & $(0.03)$ & $(0.02)$ \\
State fixed effects & & \\
Year fixed effects & Yes & Yes \\
R-squared & Yes & Yes \\
Observations & Yes & Yes \\
& 0.83 & 0.84 \\
\hline
\end{tabular}

Notes: Standard errors are robust, clustered by state and year, and appear in parentheses for independent variables. Superscripts $* * * * * *$ correspond to a 10,5 and $1 \%$ level of significance. All regressions include an intercept and are estimated using OLS. The sample includes the 50 U.S. states and covers the period of 1963-2007. Dependent variable in Column 1 (2) is the baseline statutory (average) tax rates described in the text. 'CA' is the treatment measure described in the text. 'RR' is a dummy variable that includes the states that had some positive severance tax collections during treatment years (1980-1986); 'NRR' is a dummy variable that includes the remaining states. For the list of states included in each group see Appendix. All regressions include in addition the

following controls ( $t-1)$ : real per capita GSP, real per capita state expenditures, annual rate of change in state population, annual rate of change in real per capita capital stock, real per capita federal transfers to states. Where possible, explanatory variables are in natural logarithm form. For further information on variables see data Appendix. 
Table 3: State tax rates and COWA, 1963-2007

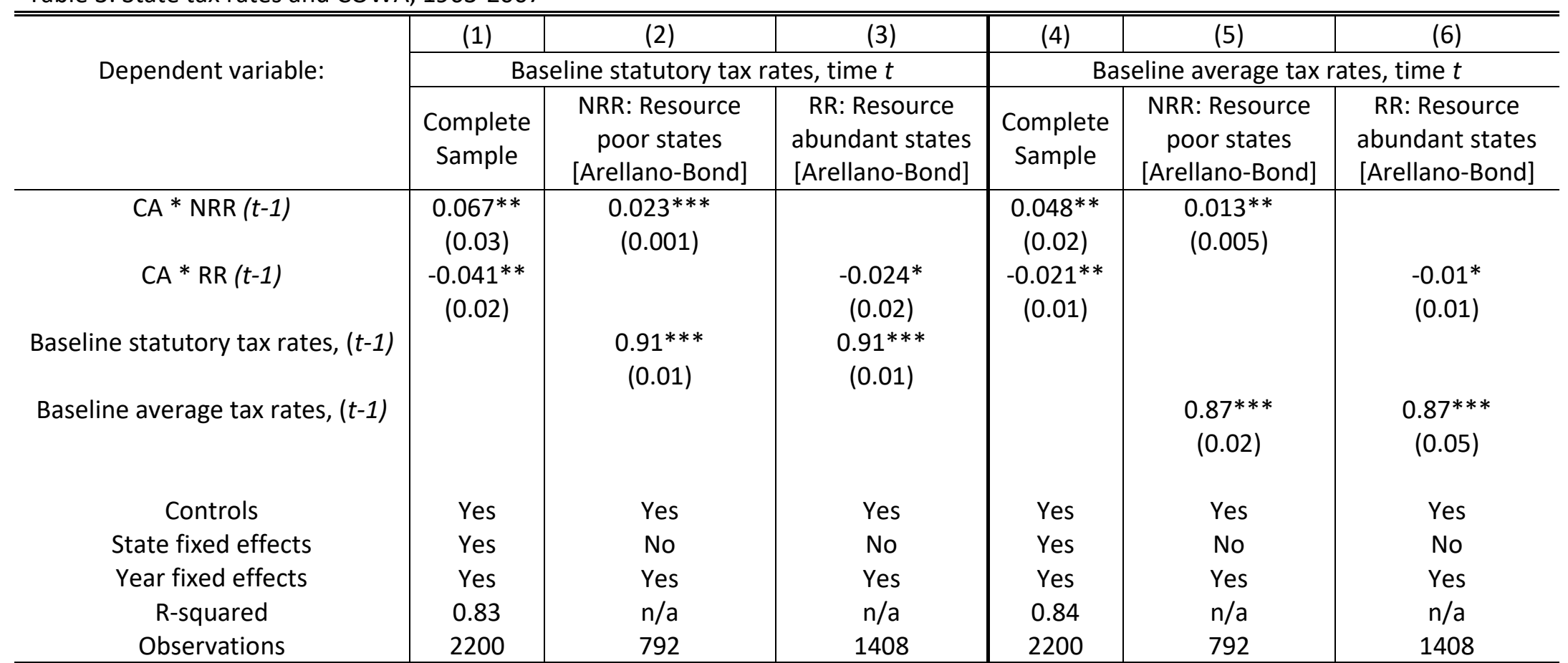

Notes: Standard errors are robust, clustered by state and year, and appear in parentheses for independent variables. Superscripts *,**,*** correspond to a 10,5 and $1 \%$ level of

significance. All regressions include an intercept. Columns 1 and 4 (2-3 and 5-6) are estimated using OLS (Arellano-Bond estimator). General sample includes the 50 U.S. states and covers the period of 1963-2007; the sample in Columns 2-3 and 5-6 is restricted to NRR/RR states (described below). Dependent variable in Columns 1-3 (4-6) is the baseline statutory (average)

tax rates described in the text. 'CA' is the treatment measure described in the text. 'RR' is a dummy variable that includes the states that had some positive severance tax collections during treatment years (1980-1986); 'NRR' is a dummy variable that includes the remaining states. For the list of states included in each group see Appendix. All regressions include in addition the following controls (t-1): real per capita GSP, real per capita state expenditures, annual rate of change in state population, annual rate of change in real per capita capital stock, real per capita federal transfers to states. Where possible, explanatory variables are in natural logarithm form. For further information on variables see data Appendix. 
Table 4: State tax rates and COWA - disaggregation, 1963-2007

\begin{tabular}{|c|c|c|c|c|c|c|}
\hline \multirow[b]{3}{*}{$\begin{array}{l}\text { Dependent } \\
\text { variable: }\end{array}$} & (1) & $(2)$ & (3) & (4) & (5) & (6) \\
\hline & \multicolumn{3}{|c|}{ Statutory tax rates, time $t$} & \multicolumn{3}{|c|}{ Average tax rates, time $t$} \\
\hline & $\begin{array}{c}\text { Top corporate } \\
\text { tax rate }\end{array}$ & $\begin{array}{l}\text { Top income } \\
\text { tax rate }\end{array}$ & $\begin{array}{l}\text { Sales tax } \\
\text { rate }\end{array}$ & $\begin{array}{c}\text { Average } \\
\text { corporate tax } \\
\text { rate }\end{array}$ & $\begin{array}{c}\text { Average } \\
\text { income tax } \\
\text { rate }\end{array}$ & $\begin{array}{c}\text { Average } \\
\text { sales tax } \\
\text { rate }\end{array}$ \\
\hline $\mathrm{CA} * \operatorname{NRR}(t-1)$ & $\begin{array}{l}-0.06 \\
(0.06)\end{array}$ & $\begin{array}{l}0.06 * * \\
(0.03)\end{array}$ & $\begin{array}{c}0.13 * * * \\
(0.03)\end{array}$ & $\begin{array}{l}-0.09 \\
(0.06)\end{array}$ & $\begin{array}{c}0.18 * * * \\
(0.05)\end{array}$ & $\begin{array}{c}0.09 * * * \\
(0.03)\end{array}$ \\
\hline $\mathrm{CA} * \mathrm{RR}(t-1)$ & $\begin{array}{c}-0.08 * * \\
(0.04)\end{array}$ & $\begin{array}{c}0.04 \\
(0.02)\end{array}$ & $\begin{array}{c}0.03 \\
(0.03)\end{array}$ & $\begin{array}{c}-0.21 * * \\
(0.09)\end{array}$ & $\begin{array}{l}0.11^{*} \\
(0.06)\end{array}$ & $\begin{array}{c}0.03 \\
(0.03)\end{array}$ \\
\hline Controls & Yes & Yes & Yes & Yes & Yes & Yes \\
\hline State fixed effects & Yes & Yes & Yes & Yes & Yes & Yes \\
\hline Year fixed effects & Yes & Yes & Yes & Yes & Yes & Yes \\
\hline R-squared & 0.81 & 0.86 & 0.91 & 0.88 & 0.78 & 0.92 \\
\hline Observations & 2200 & 2200 & 2200 & 2200 & 2200 & 2200 \\
\hline
\end{tabular}

( a 10, 5 and $1 \%$ level of significance. All regressions include an intercept, and estimated via OLS. The sample includes the 50 U.S. states and covers the period of 1963-2007. The dependent variable in Columns 1-3 (4-6) is the statutory (average) corporate/income/sales tax rates described in the text. 'CA' is the treatment measure described in the text. ' $R R^{\prime}$ is a dummy variable that includes the states that had some positive severance tax collections during treatment years (1980-1986); 'NRR' is a dummy variable that includes the remaining states. For the list of states included in each group see Appendix. All regressions include in addition the following controls (t-1): real per capita GSP, real per capita state expenditures, annual rate of change in state

population, annual rate of change in real per capita capital stock, real per capita federal transfers to states. Where possible, explanatory variables are in natural logarithm form. For further information on variables see data Appendix. 
Table 5: State spending and COWA, 1963-2007

\begin{tabular}{|c|c|c|c|c|c|c|}
\hline & $(1)$ & $(2)$ & (3) & $(4)$ & (5) & (6) \\
\hline $\begin{array}{l}\text { Dependent variable, time } t \text { (all in } \\
\text { real per capita terms): }\end{array}$ & $\begin{array}{c}\text { Total } \\
\text { expenditure }\end{array}$ & $\begin{array}{l}\text { Transpor- } \\
\text { tation }\end{array}$ & Welfare & Health & Education & Safety \\
\hline \multirow[t]{2}{*}{$\mathrm{CA} * \mathrm{NRR}(t-1)$} & $0.048 * *$ & $0.069 * *$ & $0.135 * *$ & -0.03 & 0.009 & -0.21 \\
\hline & $(0.02)$ & $(0.03)$ & 0.07 & $(0.07)$ & $(0.05)$ & $(0.13)$ \\
\hline \multirow[t]{2}{*}{$\mathrm{CA} * \mathrm{RR}(t-1)$} & 0.03 & $0.037^{*}$ & 0.04 & -0.07 & 0.06 & 0.05 \\
\hline & $(0.03)$ & $(0.02)$ & (0.09) & $(0.07)$ & $(0.06)$ & $(0.08)$ \\
\hline Controls & Yes & Yes & Yes & Yes & Yes & Yes \\
\hline State fixed effects & Yes & Yes & Yes & Yes & Yes & Yes \\
\hline Time trend & Yes & Yes & Yes & Yes & Yes & Yes \\
\hline R-squared & 0.36 & 0.32 & 0.17 & 0.04 & 0.16 & 0.07 \\
\hline Observations & 2200 & 2200 & 2200 & 2200 & 2200 & 2200 \\
\hline \multicolumn{7}{|c|}{$\begin{array}{l}\text { Notes: Standard errors are robust, clustered by state and year, and appear in parentheses for independent variables. Superscripts } *, * *, * * * \text { correspond to a } \\
10,5 \text { and } 1 \% \text { level of significance. All regressions include an intercept, and estimated via OLS. The sample includes the } 50 \text { U.S. states and covers the period of } \\
1963-2007 \text {. The dependent variable is the natural logarithm of the real per capita state government expenditure in the categories outlined in each column. } \\
\text { 'CA' is the treatment measure described in the text. 'RR' is a dummy variable that includes the states that had some positive severance tax collections during } \\
\text { treatment years (1980-1986); 'NRR' is a dummy variable that includes the remaining states. For the list of states included in each group see Appendix. All } \\
\text { regressions include in addition the following controls (t-1): real per capita GSP, real per capita state expenditures, annual rate of change in state population, } \\
\text { annual rate of change in real per capita capital stock, real per capita federal transfers to states. Where possible, explanatory variables are in natural logarithm } \\
\text { form. For further information on variables see data Appendix. }\end{array}$} \\
\hline
\end{tabular}


Table 6: State tax rates and COWA - robustness, 1963-2007

\begin{tabular}{|c|c|c|c|c|c|c|c|}
\hline \multirow[b]{2}{*}{$\begin{array}{l}\text { Dependent variable: Baseline } \\
\text { statutory tax rates, time } t\end{array}$} & $(1)$ & $(2)$ & (3) & (4) & (5) & (6) & (7) \\
\hline & $\begin{array}{l}\text { Dynamic setting } \\
\text { [Arellano-Bond] }\end{array}$ & $\begin{array}{l}\text { Shorter } \\
\text { sample }\end{array}$ & $\begin{array}{l}\text { Three period } \\
\text { framework }\end{array}$ & $\begin{array}{c}\text { State } \\
\text { division: } \\
\text { NRR no } z\end{array}$ & $\begin{array}{l}\text { State division: } \\
\text { RR dominance }\end{array}$ & $\begin{array}{l}1980 \\
\text { excluded }\end{array}$ & $\begin{array}{l}\text { Equal COWA } \\
\text { expenditures }\end{array}$ \\
\hline \multirow[t]{2}{*}{$C A * N R R(t-1)$} & $0.01^{* *}$ & $0.05 * *$ & $0.12 * * *$ & $0.06 * *$ & $0.06 * *$ & $0.07 * *$ & $0.08 * *$ \\
\hline & $(0.006)$ & $(0.024)$ & $(0.009)$ & $(0.03)$ & $(0.02)$ & $(0.03)$ & $(0.04)$ \\
\hline \multirow[t]{2}{*}{$\mathrm{CA} * \mathrm{RR}(t-1)$} & $-0.002 * *$ & $-0.03^{*}$ & $-0.01 * *$ & $-0.04 *$ & $-0.15^{* * *}$ & $-0.04^{*}$ & $-0.03^{*}$ \\
\hline & $(0.001)$ & $(0.03)$ & $(0.005)$ & $(0.04)$ & $(0.06)$ & $(0.04)$ & $(0.03)$ \\
\hline \multirow[t]{2}{*}{ Baseline statutory tax rates, $(t-1)$} & $0.96 * * *$ & & & & & & \\
\hline & $(0.009)$ & & & & & & \\
\hline Controls & Yes & Yes & Yes & Yes & Yes & Yes & Yes \\
\hline State fixed effects & Yes & Yes & Yes & Yes & Yes & Yes & Yes \\
\hline Year fixed effects & Yes & Yes & Yes & Yes & Yes & Yes & Yes \\
\hline R-squared & $\mathrm{n} / \mathrm{a}$ & 0.86 & 0.84 & 0.83 & 0.83 & 0.83 & 0.82 \\
\hline Observations & 2200 & 1400 & 150 & 2200 & 2200 & 2150 & 2200 \\
\hline
\end{tabular}

Notes: Standard errors are robust, clustered by state and year, and appear in parentheses for independent variables. Superscripts *,**,*** correspond to a 10,5 and $1 \%$ level of significance. All regressions include an intercept. Column 2-7 (1) are estimated using OLS (Arellano-Bond estimator). The general sample includes the 50 U.S. states and covers the period of 1963-2007; in Column 2 the period is 1970-1996; Column 3 averages the sample to three periods: pre-treatment, treatment, and post-treatment; in Column 61980 is excluded. The dependent variable is the baseline statutory tax rate described in the text. 'CA' is the treatment measure described in the text. 'NRR' is a dummy variable that includes the states that had no severance tax collections during all sample years (Column 4) or during treatment years (Columns 1-3 and 6-7), or states categorized as resource poor (Column 5). 'RR' is a dummy variable that includes the remaining states. For the list of states included in each group see Appendix. All regressions include in addition the following controls (t-1): real per capita GSP, real per capita state expenditures, annual rate of change in state population, annual rate of change in real per capita capital stock, real per capita federal transfers to states. Where possible, explanatory variables are in natural logarithm form. For further information on variables see data Appendix. 
Table 7: State tax rates and pre-COWA -- placebo test, 1963-2007

\begin{tabular}{c|ccc}
\hline \hline \multirow{2}{*}{$\begin{array}{c}\text { Dependent variable: Baseline statutory } \\
\text { tax rates, time } t\end{array}$} & $(1)$ & $(2)$ & $(3)$ \\
\cline { 2 - 3 } pre-CA * NRR $(t-1)$ & NRR: no z, pre- & NRR: no z, & RR \\
CA-years & all sample & dominance \\
\hline pre-CA * RR $(t-1)$ & -0.002 & -0.007 & -0.002 \\
& $(0.002)$ & $(0.01)$ & $(0.002)$ \\
& -0.0007 & -0.0007 & -0.0005 \\
Controls & $(0.0007)$ & $(0.0006)$ & $(0.0006)$ \\
State fixed effects & & & Yes \\
Year fixed effects & Yes & Yes & Yes \\
R-squared & Yes & Yes & Yes \\
Observations & Yes & Yes & 0.82 \\
& 0.82 & 0.82 & 2200 \\
\hline
\end{tabular}

Notes: Standard errors are robust, clustered by state and year, and appear in parentheses for independent variables.

Superscripts $*, * *, * * *$ correspond to a 10,5 and $1 \%$ level of significance. All regressions include an intercept, and estimated via OLS. General sample includes the 50 U.S. states and covers the period of 1963-2007. The dependent variable is the

baseline statutory tax rates. 'pre-CA' is the placebo treatment described in the text. 'NRR' is a dummy variable that includes the states that had no severance tax collections during pre-treatment-years, 1972-1979 (Column 1) or over the whole sample period (Column 2), or states categorized as resource poor (Column 3). 'RR' is a dummy variable that includes the remaining states. For the list of states included in each group see Appendix. All regressions include in addition the following controls ( $t$ -

1): real per capita GSP, real per capita state expenditures, annual rate of change in state population, annual rate of change in

real per capita capital stock, real per capita federal transfers to states. Where possible, explanatory variables are in natural

logarithm form. For further information on variables see data Appendix. 
Table A1: COWA and estimated reduction in domestic oil production

\begin{tabular}{c|cc}
\hline \hline Year & $\begin{array}{c}\text { Million } \\
\text { barrels }\end{array}$ & $\begin{array}{c}\text { Share of oil } \\
\text { output }\end{array}$ \\
\hline 1980 & 294 & 7.9 \\
1981 & 310 & 8.3 \\
1982 & 232 & 6.2 \\
1983 & 164 & 4.4 \\
1984 & 161 & 4.2 \\
1985 & 114 & 3.0 \\
1986 & 0 & 0 \\
$1980-1986$ & 1268 & 4.8 \\
\hline \\
The table presents the estimated drop in domestic oil \\
production, in millions of barrels and as share of total oil \\
output, due to the 1980 Crude Oil Windfall Act, under \\
the assumption that the price elasticity of oil supply is 0.8 \\
(Source: Lazari (2006)).
\end{tabular}


Table A2: Federal spending and COWA, U.S.-level time-series analysis, 1963-2007

\begin{tabular}{|c|c|c|c|c|c|c|c|c|c|}
\hline & (1) & $(2)$ & (3) & (4) & (5) & $(6)$ & (7) & (8) & (9) \\
\hline $\begin{array}{l}\text { Real federal spending, } \\
\text { at time } t \text {, on: }\end{array}$ & Energy & $\begin{array}{c}\text { Regional } \\
\text { development }\end{array}$ & $\begin{array}{c}\text { Transpor- } \\
\text { tation }\end{array}$ & $\begin{array}{l}\text { Income and } \\
\text { social security }\end{array}$ & Housing & Education & $\begin{array}{c}\text { Health and } \\
\text { Medicare }\end{array}$ & $\begin{array}{l}\text { National } \\
\text { defense }\end{array}$ & Others \\
\hline COWA, $(t-1)$ & $\begin{array}{c}0.44^{* * *} \\
(0.05)\end{array}$ & $\begin{array}{l}0.16^{*} \\
(0.08)\end{array}$ & $\begin{array}{l}0.13^{* *} \\
(0.06)\end{array}$ & $\begin{array}{l}0.05^{* *} \\
(0.02)\end{array}$ & $\begin{array}{l}-0.44 \\
(0.41)\end{array}$ & $\begin{array}{c}0.23 \\
(0.19)\end{array}$ & $\begin{array}{c}0.07 \\
(0.49)\end{array}$ & $\begin{array}{c}0.73 \\
(0.86)\end{array}$ & $\begin{array}{c}0.28 \\
(0.31)\end{array}$ \\
\hline Controls & Yes & Yes & Yes & Yes & Yes & Yes & Yes & Yes & Yes \\
\hline Time trend & Yes & Yes & Yes & Yes & Yes & Yes & Yes & Yes & Yes \\
\hline R-squared & 0.68 & 0.42 & 0.93 & 0.73 & 0.15 & 0.77 & 0.96 & 0.67 & 0.77 \\
\hline Observations & 45 & 45 & 45 & 45 & 45 & 45 & 45 & 45 & 45 \\
\hline
\end{tabular}

Notes: Standard errors are robust, and appear in parentheses for independent variables. Superscripts $*, * *, * * *$ correspond to a 10,5 and $1 \%$ level of significance. The sample pertains to the U.S. and covers the period of 1963-2007. All regressions include an intercept, a time trend, real per capita U.S. GDP (t-1), the real federal revenues net of those from CA (t-1), and the real federal expenditures net of those represented by the dependent variable (t-1). 'COWA' is the real annual federal tax receipts collected under the 1980 Crude Oil Windfall Act during $1980-1986$. The dependent variable is real federal spending in the categories outlined in the table; 'Others' category is an aggregate of the following sub-groups: International affairs, Science, Agriculture, Justice, General Government, and Allowances. Data retrieved from the U.S. Office of Management and Budget. 


\begin{tabular}{l|cccc}
\hline \hline & Mean & Std. Dev. & Min. & Max. \\
\hline Real federal spending on energy (Million \$) & 7263.71 & 7657.392 & 10.7888 & 31761.3 \\
Real federal spending on regional development (Million \$) & 15387.3 & 9280.487 & 3180.06 & 57769.4 \\
Real federal spending on transportation (Million \$) & 46675.3 & 13944.52 & 25462.6 & 77635.1 \\
Real federal spending on income and social security (Million \$) & 544012 & 261009.6 & 139053 & 983197 \\
Real federal spending on housing (Million \$) & 16693.5 & 21982.37 & 343.49 & 111148 \\
Real federal spending on education (Million \$) & 58113.7 & 23678.59 & 8077.56 & 125670 \\
Real federal spending on health and Medicare (Million \$) & 100129 & 83402.42 & 8038.78 & 275074 \\
Real federal spending on 'others' (Million \$) & 104762 & 21127.84 & 69876.3 & 155233 \\
Real federal spending on national defense (Million \$) & 379835 & 79652.27 & 272297 & 569246 \\
U.S. real per capita GDP & 28558.1 & 12491.11 & 9187.27 & 49661.3 \\
Real annual collections from CowA (Million \$) & 1738.51 & 4862.456 & 0 & 23252 \\
Real federal revenues net of those from COWA (Million \$) & 1196658 & 775746.7 & 80939.4 & 2786579 \\
\hline Notes: Figures are in 2009 prices. & & & &
\end{tabular}




\begin{tabular}{|c|c|c|c|c|c|c|c|c|}
\hline & \multicolumn{4}{|c|}{ RR states } & \multicolumn{4}{|c|}{ NRR states } \\
\hline & Mean & Std. Dev. & Min. & Max. & Mean & Std. Dev. & Min. & Max. \\
\hline Real per capita GSP & 30567.24 & 10729.60 & 11351.48 & 110866 & 32550.13 & 11230.95 & 11833.68 & 71982.8 \\
\hline Real COWA collections, 1980-1986 (Million \$) & 11176.14 & 6825.18 & 2251 & 23252 & 11176.14 & 6825.18 & 2251 & 23252 \\
\hline $\begin{array}{l}\text { Real state-specific federal expenditures per capita (net of } \\
\text { transfers and payments to individuals), 1980-1986 (Thousand \$) }\end{array}$ & 0.687 & 0.422 & 0.149 & 2.120 & 0.677 & 0.462 & 0.082 & 2.151 \\
\hline $\begin{array}{l}\text { Treatment effect }(C A) \text {-- COWA-driven real state-specific federal } \\
\text { expenditures per capita (net of transfers and payments to } \\
\text { individuals), 1980-1986 (Thousand \$) }\end{array}$ & 0.041 & 0.032 & 0.006 & 0.146 & 0.038 & 0.026 & 0.005 & 0.137 \\
\hline Real per capita federal transfers to state governments & 577.97 & 529.70 & 34.76 & 3916.77 & 564.92 & 489.71 & 27.20 & 2481.86 \\
\hline Real per capita state government expenditure & 3419.98 & 2045.92 & 873.63 & 17485.5 & 3631.17 & 1640.23 & 852.14 & 8416.28 \\
\hline Annual rate of change in real per capita capital stock & 0.02 & 0.03 & -0.07 & 0.42 & 0.02 & 0.03 & -0.08 & 0.31 \\
\hline Annual rate of change in population & 0.01 & 0.01 & -0.06 & 0.10 & 0.01 & 0.01 & -0.03 & 0.10 \\
\hline Baseline statutory tax rates & 0.05 & 0.02 & 0 & 0.11 & 0.05 & 0.02 & 0.004 & 0.14 \\
\hline Baseline average tax rates & 0.02 & 0.007 & 0.005 & 0.05 & 0.030 & 0.007 & 0.009 & 0.05 \\
\hline Average corporate tax rates & 0.003 & 0.003 & 0 & 0.04 & 0.004 & 0.002 & 0 & 0.01 \\
\hline Average income tax rates & 0.01 & 0.009 & 0 & 0.04 & 0.02 & 0.009 & 0 & 0.03 \\
\hline Average sales tax rates & 0.03 & 0.01 & 0.003 & 0.05 & 0.03 & 0.01 & 0.007 & 0.05 \\
\hline Top corporate tax rate & 0.05 & 0.03 & 0 & 0.12 & 0.07 & 0.03 & 0 & 0.12 \\
\hline Top income tax rate & 0.05 & 0.04 & 0 & 0.17 & 0.06 & 0.04 & 0 & 0.2 \\
\hline Sales tax rate (statutory) & 0.04 & 0.02 & 0 & 0.07 & 0.04 & 0.02 & 0 & 0.08 \\
\hline Real per capita state government expenditure on education & 1153.81 & 549.94 & 170.92 & 3871.36 & 1084.81 & 474.35 & 138.54 & 3628.70 \\
\hline Real per capita state government expenditure on health & 93.45 & 77.38 & 3.97 & 645.35 & 111.58 & 92.73 & 5.55 & 500.34 \\
\hline Real per capita state government expenditure on transportation & 392.24 & 226.41 & 123.96 & 2192.85 & 328.04 & 126.63 & 110.40 & 866.01 \\
\hline Real per capita state government expenditure on public welfare & 565.09 & 395.95 & 43.23 & 2549.25 & 686.67 & 489.63 & 65.86 & 2507.59 \\
\hline Real per capita state government expenditure on public safety & 70.76 & 71.49 & 2 & 463.52 & 79.79 & 75.62 & 3 & 428.67 \\
\hline
\end{tabular}


Figure 1: Real Crude Oil Prices, 1963-2007

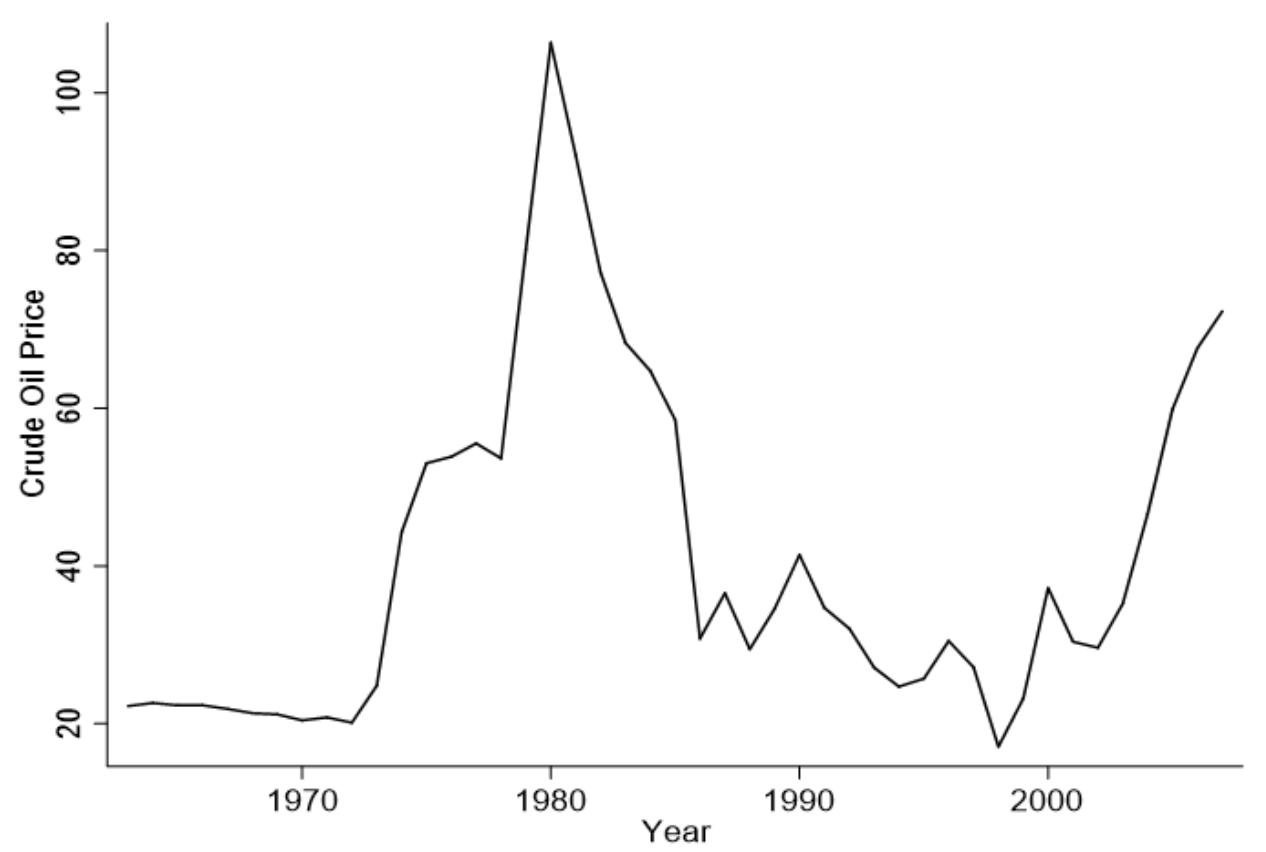

Notes: Figure presents the annual average real crude oil prices (in \$/Barrel, 2015 prices), 1963-2007 (Source: World Bank). 
Figure 2: Annual Receipts from the 1980 Crude Oil Windfall Act, 1980-1986

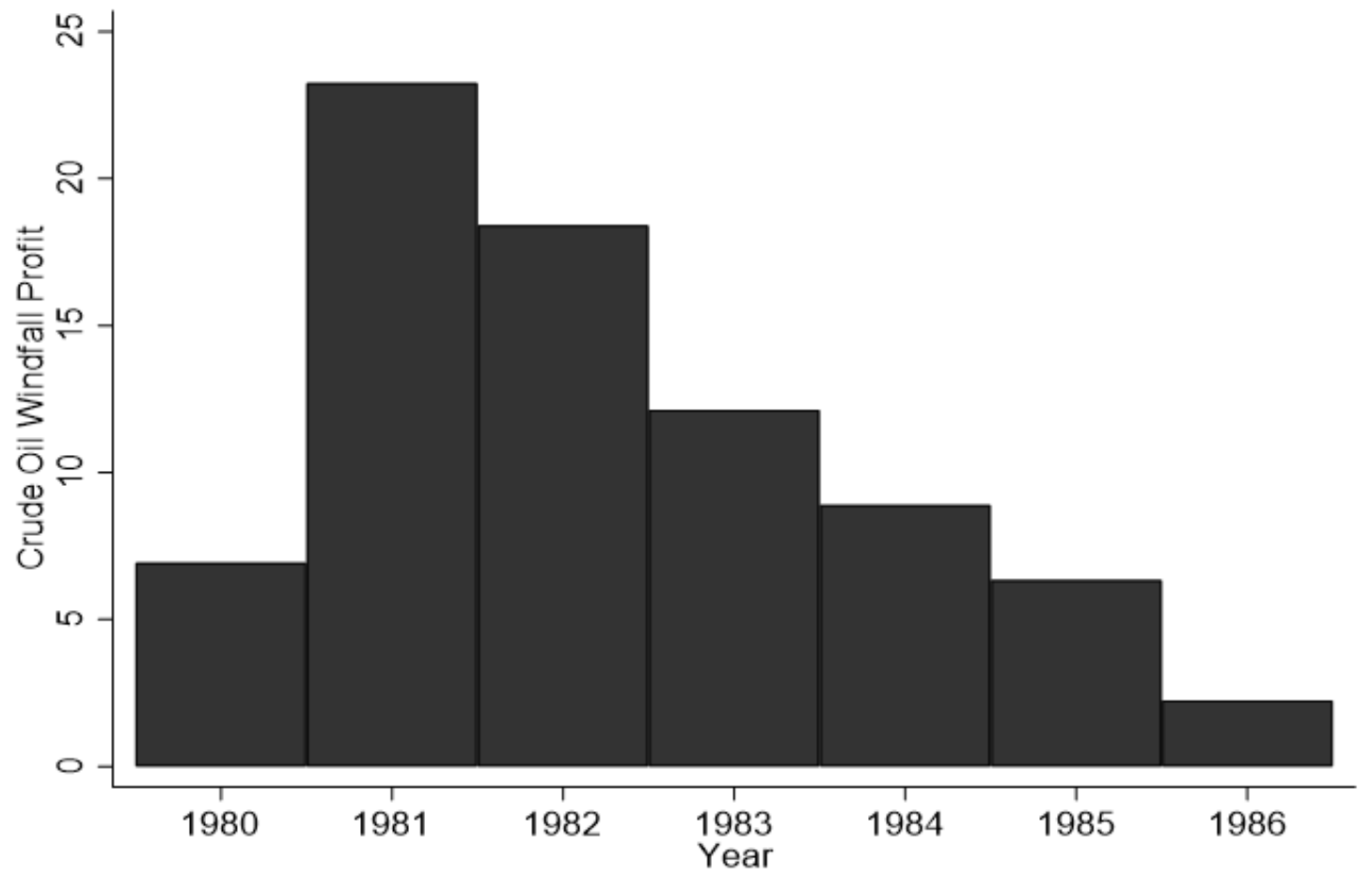

Notes: Figure presents the annual receipts from the 1980 Crude Oil Windfall Act (billions \$, 2013 prices), 1980-1986, collected by the U.S. Federal Government (Source: U.S. Office of Management and Budget). 
Figure 3: Average Annual Share of Severance Tax Revenues in Total Tax Revenues across U.S. states, 1963-2007

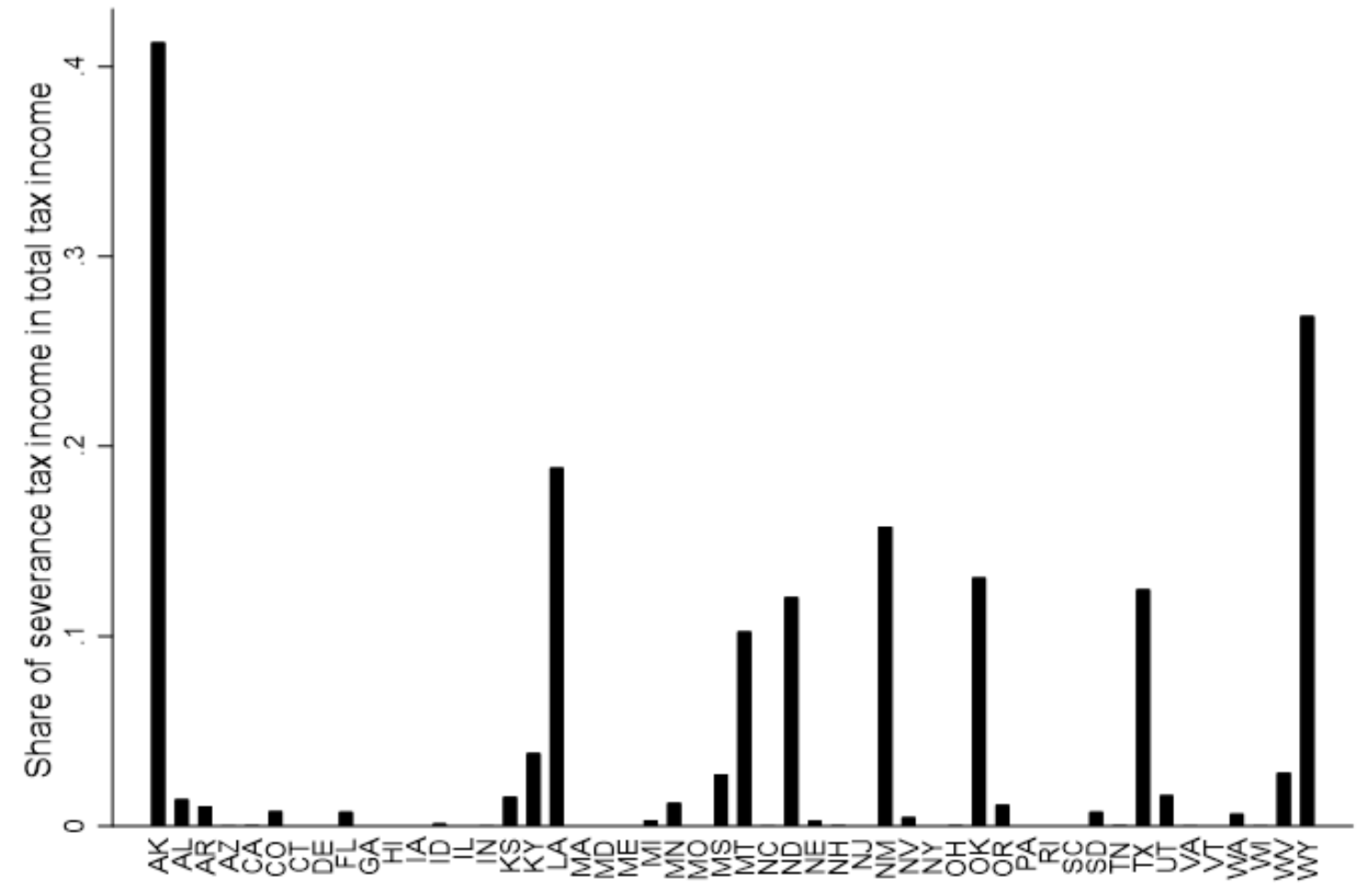

Notes: Figure presents the average annual share of severance tax revenues in total tax revenues, 19632007, across U.S. states (Source: U.S. Census Bureau). 
Figure 4: Average Annual Federal Expenditures Per Capita across U.S. states, 1981-1986

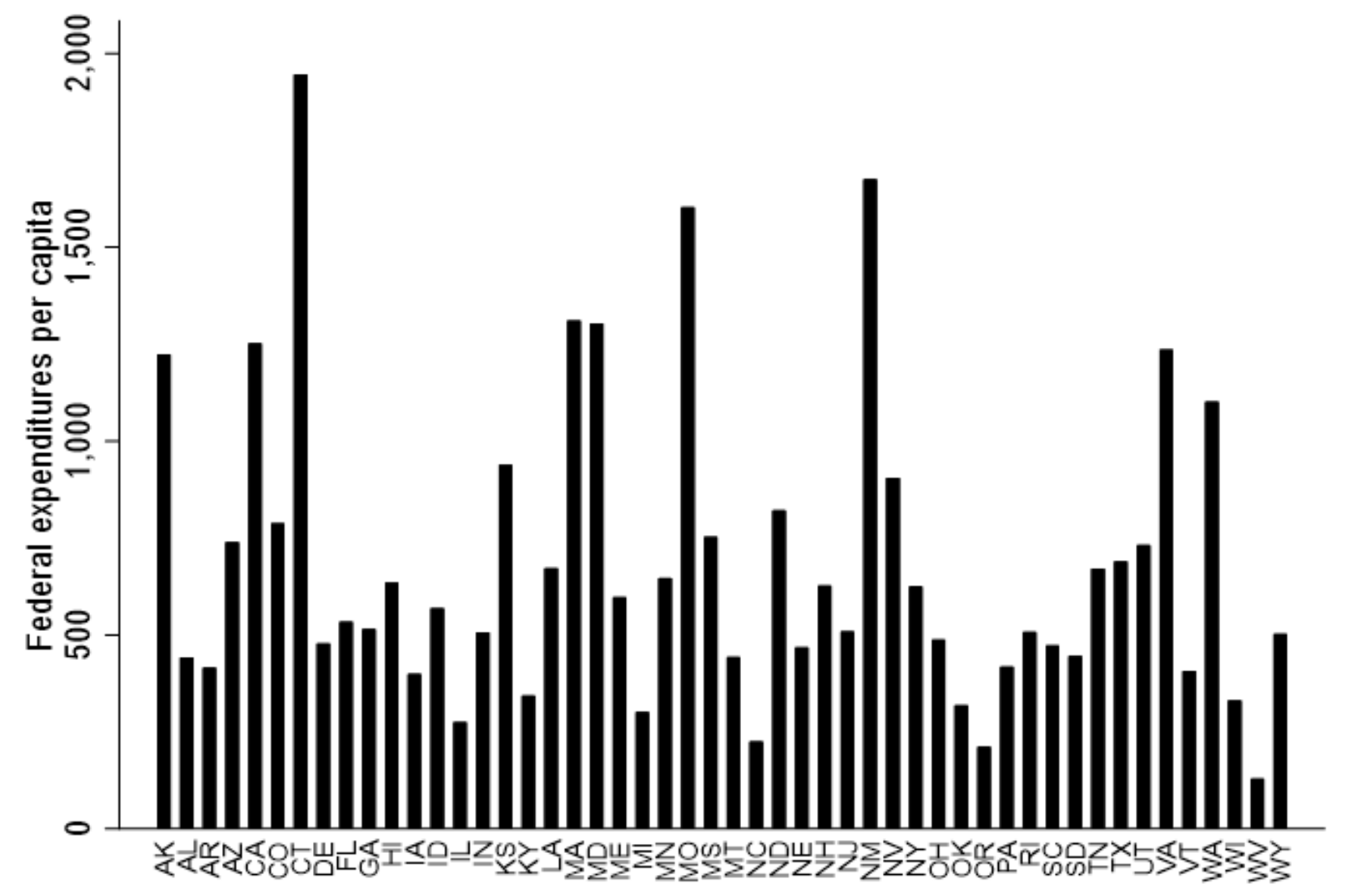

Notes: Figure presents the average annual real federal expenditures per capita, net of transfers and direct payments to individuals, U.S. states, for 1981-1986. 
Figure 5: Federal Expenditures -- Resource Rich vs. Resource Poor states, 1981-1986

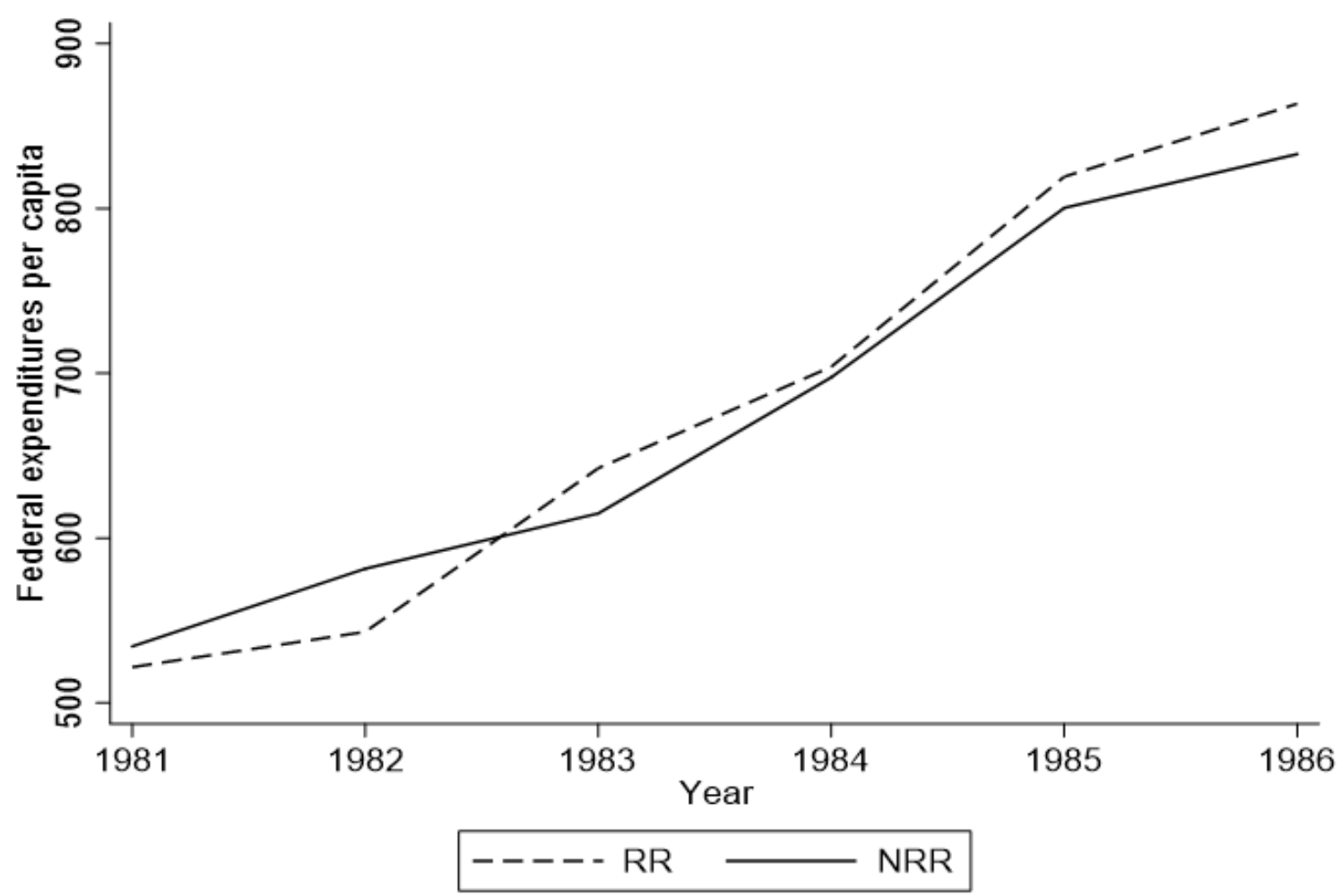

Notes: Figure presents the average annual real federal expenditures per capita, net of transfers and direct payments to individuals, across resource rich (RR) and resource poor (NRR) states, for 1981-1986. See Appendix for the list of states that are included in each of the groups as well as the definition for being classified under each. 
Figure 6: Vertical Tax Response -- Total Difference-in-Differences, 1963-2007

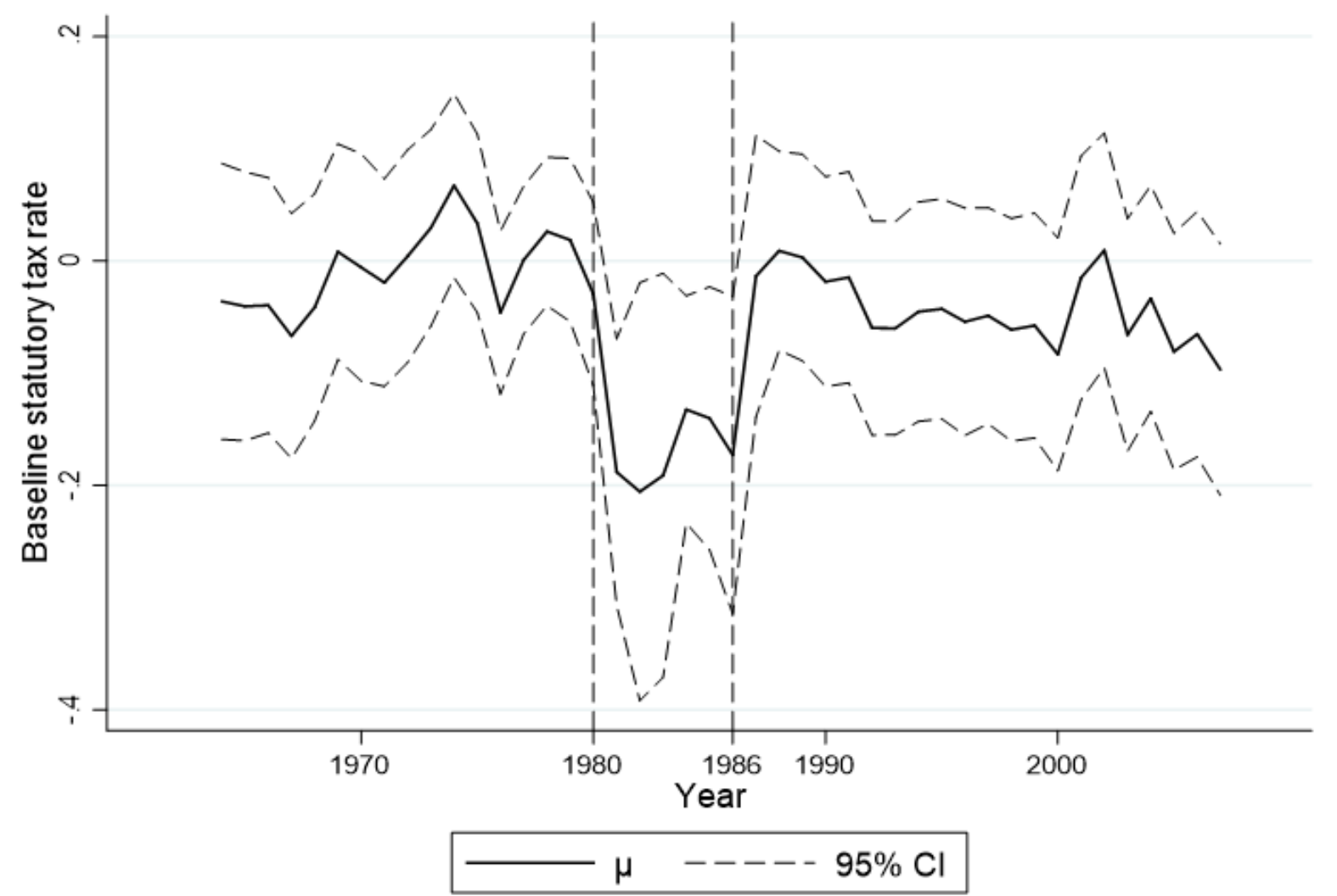

Notes: Figure presents the estimates of the coefficient on CA*RR interacted with the sample years (1963-2007), with 95\% confidence intervals, under the specification adopted in Column 1 of Table 2 with the year fixed effects excluded. The reference year is 1963. CA takes the value 1 in non-treatment years. See Appendix for the definition and sources of the variables included, and for the list of states that are included in the RR group and the definition for being classified in it. 
Figure 7: Vertical Tax Response -- Resource Rich vs. Resource Poor states, 1963-2007

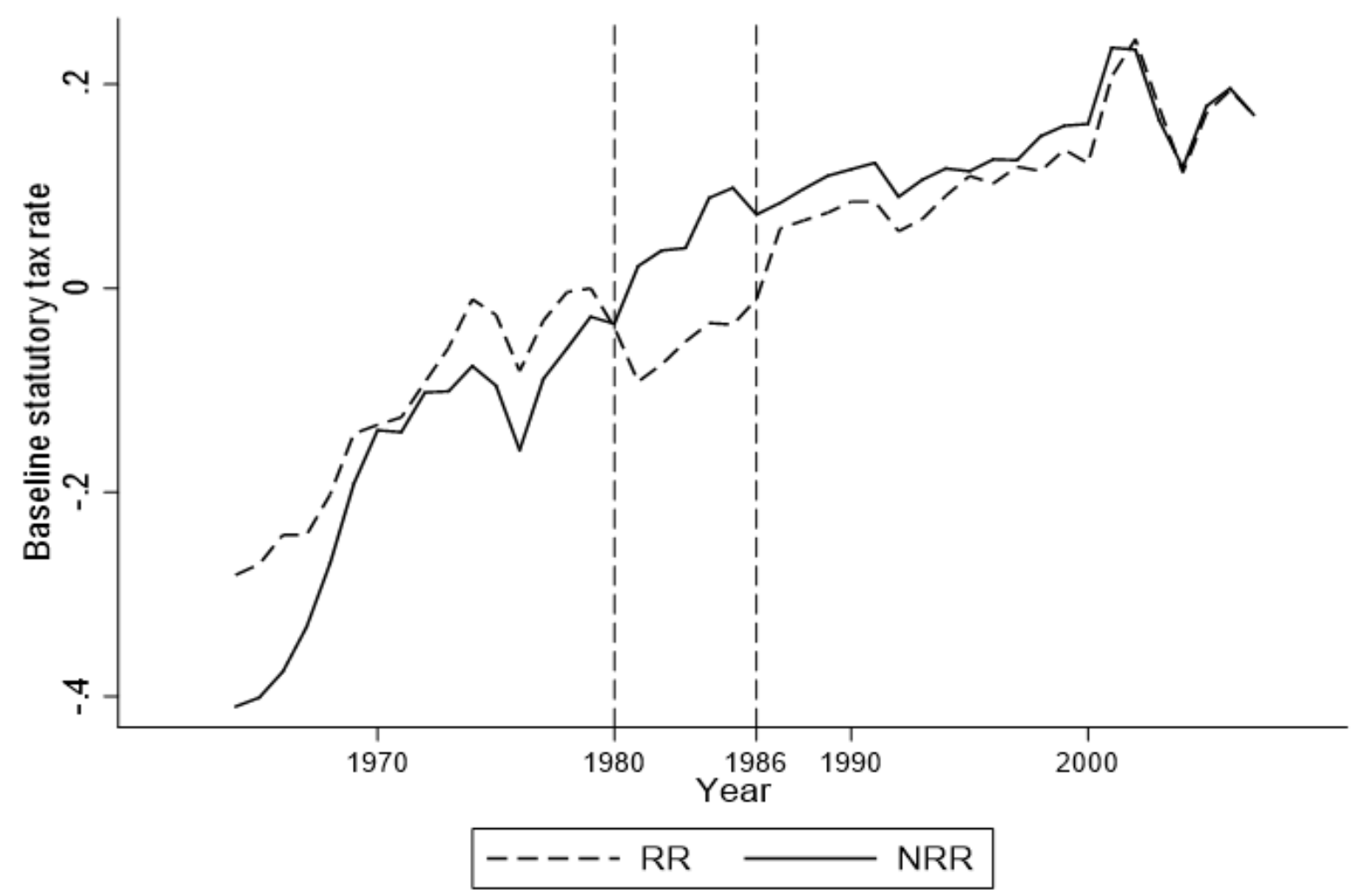

Notes: Figure presents the estimates of the treatment (CA) interacted with the sample years (1963-2007), for resource rich (RR) states VS. resource poor (NRR) states, under the baseline specification (as per Column 1 of Table 3 ) with the year fixed effects excluded. The reference year is 1963. CA takes the value 1 in non-treatment years. See Appendix for the definition and sources of the variables included, and for the list of states that are included in each of the groups as well as the definition for being classified under each. 